\title{
Design, Analysis, and Optimization of RTG for Solar Polar Mission
}

\author{
A. Schock \\ A. Shostak \\ H. Sookiazian
}

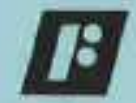

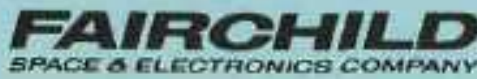

Germaniown, Md. 20767

JUNE 1,1979 
DESIGN, ANALYSIS, AND OPTIMIZATION OF RTG FOR SOLAR-POLAR MISSION

A. Schock, A. Shostak, and H. Sookiazian

Fairchild Space and Electronics Company Germantown, Maryland 20767

June 1,1979

ABSTRACT

The paper presents the canceptual design of an RFG, exploying stacked radioisotope hest source modules and siffcon-Rernanium therasefoctric couples, for isse on the joint NASA/ESA Intermational 5olor-Polar Mission, to be launched in carly 5983.

The use of stacked beat source podules in RTOs requires a structural support systen which holds the stack together during lanch, but allows it to disassenble when the generator housing nelte during reentry. This is a nuch nore difficult support problen thain in the case of a monolitekic heat source. A proposed, ifght-veight sctiene for solving this problen is described and anolyzed. A uetalled analytical aodel of the RTO and the spacecraft to which it is attached was constructed, and a NASTRAN malysiy was carried out to assess the structural perfomance of the heat source support schene under differential thermal expsesion and dyanic launch losds, to deternine the systen's characteristic frequencios, the loads transinitted to the HTG, and the resultant stresses and displacements. The analytical results presented confirn the structural feasibility of the heat source support schene. The paper also describes a detailed thernal analysis and a cosputer proyratt which, for a given set of assumptions and ground rules, can rapidty exanine thousands of design variations and deterwisn the conbination of design paraneters which wh11 ninimize the RTG weight for il given power autpat. Graphical results are presented to lilustrate design trends and clarify the optinizatian procedure. The generated results lesd to interesting and sotewhst unexpected canclusions about optinum design parameters, the relative constancy of RTG specifie powur over a wide poher range, coaparisens between sangle and split HTGs, sensitivity to variations in heat source nodule design, weight comparisons with the Nen hro, and conparative kTG weights for different housing and radistor fin nateriais.

\section{INTRODUCTION}

At the request of the Department of Energy's Advanced Nuclear Systens and Products Division, Fairchild Space and Electronics Company* has been conducting conceptual desiga studies for a light-weight Radioisotope Thermoelectric Generator (RTG), to be used on the joint NASA/ESA International Solar-Polar Mission (ISPM). That mission calls for two spacecraft, develaped under the respective direction of NASA/JPL and ESA, for scientific explorations outside the earth's ecliptic plane [1]. The two spacecraft are to be. launched simultaneously aboard the shuttle, and boosted by the IUS upper stage into long elliptical orbits towards Jupiter, whose gravitational pul1 heips to lift them out of the ecliptic plane. As illustrated in Figure 1, the two spacecraft will arrive above the sun's North and South poles about four years after launch.

Each spactecraft needs a sun-independent nuclear power system, capable of delivering about 250 watts at the end of mission. Since both spacecraft appear to be severely weight-limited, minimization of the RTC's weight (without sacrifice of reliability) is of crucial importance.

*under Contract EN 77-C-02-4281
Fig. I - SOLAR POLAR MISSION PLAN

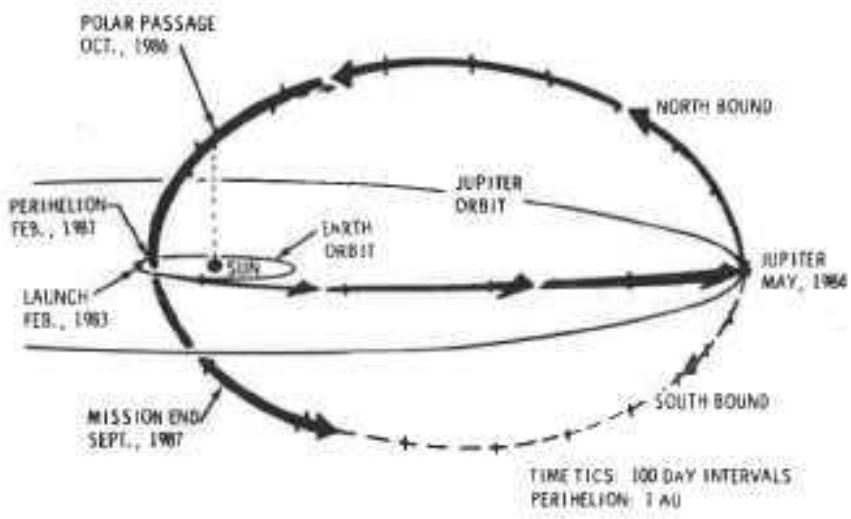

The Solar-Polar RTG design is to be based on the use of discrete heat source modules which are currently under development at Los Alamos (LASL). The design concept under development is called the General Purpose Heat Source (CPHS), since the modules can satisfy a wide range of power conversion systems, power levels, and space missions. Each module contains. within it the necessary safety provisions to ensure fuel retention under all credible abort modes.

Since some of the required safety verification tests are still incomplete, the exact heat source module weight is not yet defined at the time this is written. However, preliminary results indicate that the use of a modular heat source will permit a significantly lower RTG weight than the monolithic type of heat source used in previous missions. For example, with the heat source of the Multi-Hundred-Watt (Miw) RTG used previously on the Voyager mission, it would not be possible to meet JPL's present weight goal for the ISPM power system. By contrast, current designs of the modular heat source make it possible to meet that goal, with some margin left over to cope with anticipated contingencies: This explains the notivation for using a new heat source, still under development.

In the course of carrying out the power system design study, it became apparent that the use of a stacked modular heat source entails special design problems not present in the case of the monolithic heat sources used on previous misslons, such as the one in the MAW RTC. A discussion of those special problems, a proposed Iight-weight solution, and a structural analysis to assess it 5 viability will be presented in Section II. 
In addition to the new heat source, DOE had also planned to use a new thermoelectric conversion naterial in the ISPM flight generators. The intended material consisted of copper selenide for the P-legs and gadolinium selenide for the N-legs. Based on single-element tests under ideallzed laboratory conditions, these seleride materials offered the possi. bility of significantly higher conversion efficiencies than could be obtained with the silicon-germanium thermoelements that were used on previous missions,

By the end of 1978 , the promised performance level of the selenide elements had not yet fully materialized. Nor had the developer demonstrated the lovels of reproducibility and performance stability, in a practical engineering configuration, which would bo required for a reliable flight system. In view of the many unresolved problems and the resultant risk to NASA's ISPM progran schedule, DOE decided, at the beginning of 1979 , not to use selenide convorters in the ISPM generators. Instead, these generators will employ Si-Ge converters, which were successfully used in earlier flight systens (e.\&., on NASA's Voyager mission to Jupiter and Saturn).

Silicon-germanium thernoelements are well characterized, and should therefore present much less risk to the progran. On the other hand, since the thermoelectric efficiency of Si-Ge elements $(-7.5 \%)$ is considerably lower than the promised efficiency of Se elements $(-11,3 \%)$. they require approximately $50 \%$ more heat source modules than originally anticipated. The resultant weight increase is difficult to accommodate on the ISPM spacecraft, which is 5everely weight limited. This makes it imperative to minimize the weight of all other RTG components; without, of course, impairing the generator's reliability and long-term performance stability required for the mission.

In view of the problems and delays encountered on the selenide RTG program, DOE was most anxious to avoid any programmatic and schedule risks on the S1-Ge RTG progran for ISPM. Fairchild was therefore instructed to base its conceptual design as far as possible on proven converter technology. Specifically, this meant the same hot-junction temperature $\left(1000^{\circ} \mathrm{C}\right)$, same thermoelectric element design (except for minor dimensional changes, where necessary), and the same thermal insulation system as in the MHW RTGs. It also meant conductive radiator fins, without heat pipes.

(Considerable weight reductions are possible if these constraints are removed for future systems\}.

With the above ground rules, the design of the major system components, including the heat source modules, the insulation system, and the thermoeleacnts and their associated hardware, are essentially outside the control of the RTG designer. Thus, the only decisions left to the designer are how to put those components together to minimize the RTG weight. Principally, these decisions include the arrangement for supporting the modular heat source stack and applying the required proloads, the mechanical layout of the thermoelectric converter and the electrical layout of its series-paralleI network, the design of the RTG housing and end caps, and the choice of the coldjunction temperature and the design of the radiator fins. These items form the subject of this paper, Section II describes the rationale, major components, and topology of the RTG design evolved; Section III describes a detailed structural analysis to assess the viability of the proposed heat source support scheme under anticipated dynanic Iaunch loads; and Section IV describes the parametric optinization studies performed and their results.

\section{DESIGN DESCRIPTION AND RATIONALE}

The heat source modules under development at LASL have a thermal power level of 250 watts each. As illustrated in Figure 2 , each nodule contains four cylindrical 62.5-watt $238 \mathrm{puO}_{2}$ fuel pellets clad in iridium shells. Each capsule is surrounded by a double shell of pyrolitic graphite. The four asseriblies are contained in thick-walled impact shells and aeroshells made of a graphitic material consisting of a carbon-bonded, three-dimensional, carbon-fiber structure. The purpose of the above components is to prevent fuel release under all credible abort conditions, before, during, or after launch.

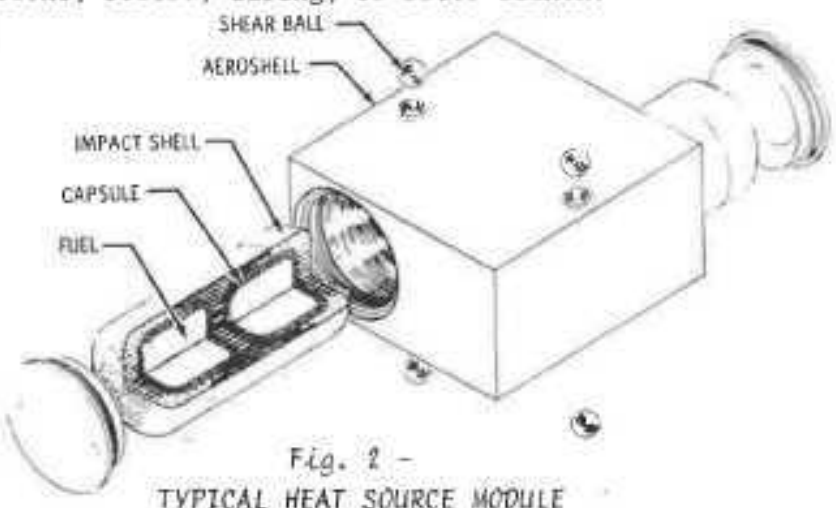

The rationale of the heat source module design and the extensive test progran to demonstrate its. safety will not be discussed here. The present paper deals not with the heat source module itself, but with its use in a practical RTG design.

The heat source module depicted in Figure 2 has typical dimensions of $3.6 \times 3.6 \times 2$ inches and weighs is little over 3 lbs. The exact values are still uncertain, since the design dimensions have not yet been finalized at the time this is written.

The basic building block of the thermoelectric converter is the $S i-G e$ unicouple depieted in pigure 3 . This is essentially identical to the units built by RCA for GE's MHW RTGs, which were successfully used on NASA's Voyager mission. It contains two rectangular Si-Ge legs, bonded to a Si-Mo hot shoe, which is about 0.9 -inch square. The hot shoe serves as the couple's hot junction and heat receiver. The thermoelectric legs are wrapped with tightly-wound quartz yarn; to provide electrical isolation between the couples and the metallic radiation shields described below.

Fig. 3 - THERMOELECTRIC ELEMENT (UNICOUPLE)

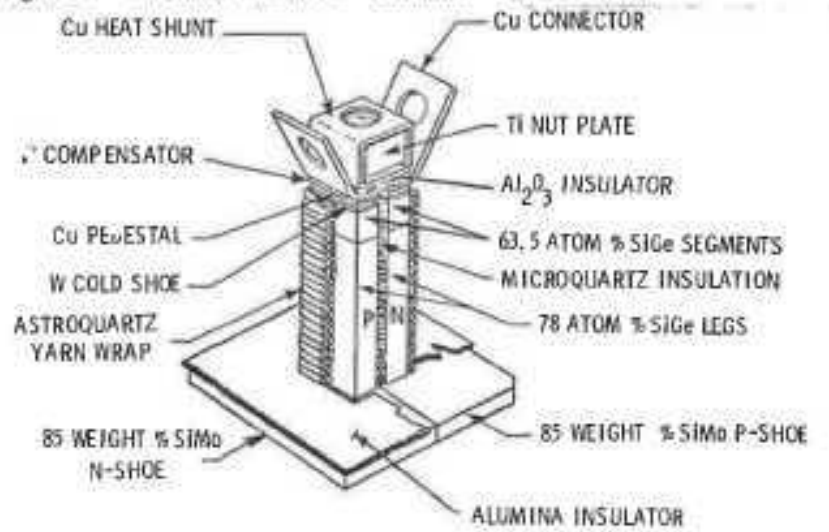

The cold ends of the Si-Ge Iegs are bonded successively to flexible copper straps (for electrical connections to other couples), a ceranic wafer (for thermal conduction and electrical isolation between the couple and the generator housing), and a flexible heat shunt (to provide a conpliant heat path to the housing). The couples and their fabrication have been described in dotail in earlier publications [2], and their performance and performance stability are well character. ized. 
The thernal insulation between the thernoelectric couples is also identical to that used in the MHN RTGS [3]. It consists of about 60 layers of $0,0003^{\prime \prime}-$ thick molybdenum foll, alternating with a sinilar number of open-weave quartz-cloth spacer5. The insulation pack age is about 0.70 inch thick. An appreciably 1ighter RTG could have been designed by using a thinner insulation package and shorter thermoelements, but this would have involved too great a departure from proven MHW technology, and was, therefore, rejected for the ISPM system.

To provide the necessary unicouple penetrations through the thermal insulation package, square holes are punched through each layer at appropriate locations. In the Fairchild design, the insulation layers are then wound into a cylindrical configuration, with the square holes carefully registered by neans of an assenbly fixture, to permit insertion of the quartz-wrapped unicouples. After insertion, the flexible copper straps of neighboring couples are connected to form the desired series-parallel network. As in the MHW RTG, a mounting screw with a C-ring seal is used to mount each unicouple to the inside of the generator's beryllium housing.

As shown in Figure 4 , there is a ring of sixteen couples around the circumference of the RTG, arranged in four groups of four parallel couples each. Series connections between groups are made between rings, in the generator's axial direction. The hot shoes of the couple rings form an essentially cylindrical cavity in which the stack of square heat source nodules is located. The RTG's housing, like the insulation package, is also cylindrical. A square or octagonal housing circumference aight permit a lower R'T weight, but would be harder to fabricate, particularly in beryl1ium.

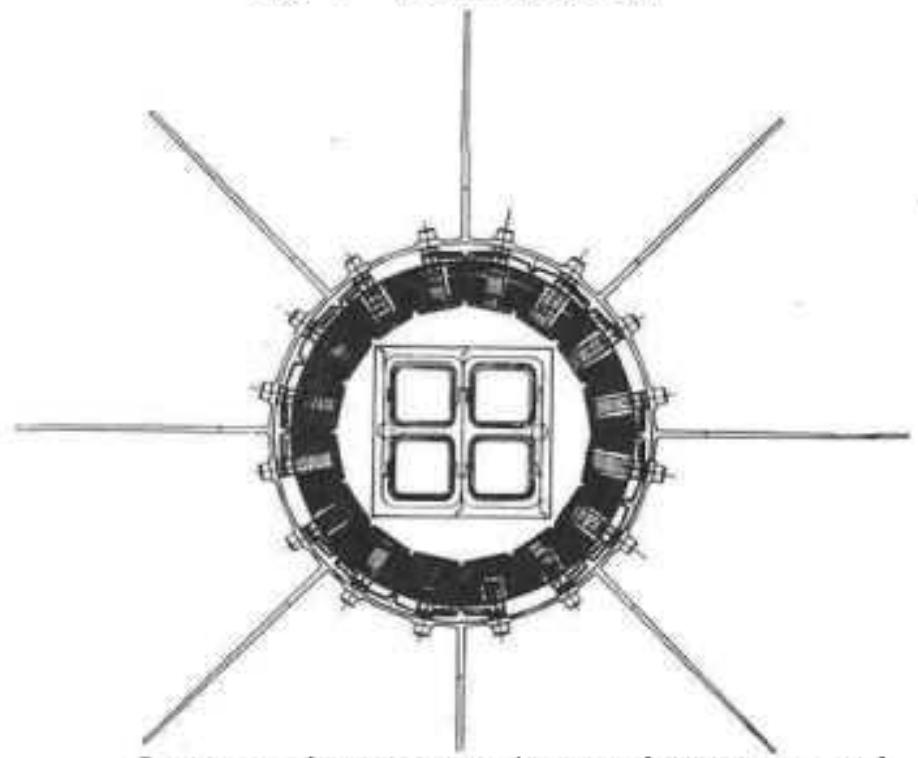

In space, the generacor is vented to vacuum, and heat transfer fron the heat source stack to the hot shoes is by radiation only. As seen, there is no contact between the hot shoes and the heat source. A typical heat source stack consists of about 18 individual modules, and is over 36 inches long. With the module stack supported only at its ends, a very high axial preload-- of the order of 10,000 1bs--is required to keop the stack from falling apart under the influence of lateral launch loads. On the other hand, to retain the full safety benefit of the nodular design concept, the heat source support structure must allow disassembly of the module stack if the RTG housing burns off during reentry. This presents a difficult design problen, much nore so than for the case of a monolithic heat source like MH.
The claimed advantages of a modular heat source (as opposed to a monolithic heat source) include better scalability to a variety of power levels without need for safety requalification), improved testability in existing safety test facilities, lower weight and snaller size for a given level of safety, and/ar better safety margins for a given weight and size. The last two advantages derive primarily froa the heat source's lower impact velocity (after reentry), which permits lighter and smaller impact protection nembers.

The individual heat source modules have a substantially lower impact velocity than a monolithic heat source because of their lower ballistic coefficient $\left(K / C_{d} A\right)$. But this advantage only accrues if the modular heat source stack disassembles during reentry. Without disassembly, the impact velocity of a modular heat source would not be significantly lower than that of a monolithic heat source.

To ensure disassembly of the heat source prior to impact, the structural members which hold the nodular stack together must cone apart during reentry, to release the individual heat source modules. This precludes the use of refractory metal straps for tying the stacked modules together. The use of nonrefractory (e.g., superalloy) straps or tie rods also appears impractical, because of inadequate strength at the anticipated operating and launch tenperatures.

The required RTG structure must not only support the heat source during launch, but must also prevent the modular stack from falling apart under the influence of the severe lateral launch loads. This latter requirement would not exist in the case of a monolithic heat source.

The RTG for the Solar-Polar mission typically requires a stack of 18 heat source nodules, for a total thermal power of 4500 watts at the beginning of life. Thus, a typical heat source stack is over 36 inches long and weighs about 601 bs.

The axinl and lateral loads to which the heat source will be subjected during launch depend on the inputs from the space shuttle and the IUS, In addition, the loads on the heat source stack depend on the amplification and damping characteristics of the spacecraft and RTG structures. None of the above are yet fully defined, but axlal and lateral loads of about 40 G are anticipated. (See Section III)

As already explained, the heat source stack cannot be held together by high-tenperature straps or tie rods, since they may prevent disassembly during reentry. Rather, the heat source stack must be held together by the RTG's low-temperature housing, which will usually melt during reentry, There are, of course, abort modes (e.g., a sub-orbital launch failure) in which the housing will not melt, and the gonerator will impact without prior disassembly. But that case does not present a special safety problem, because the ballistic coefficient of the assembled generator is low enough to ensure an adequately fow impact velocity. On the other hand, if the generator housing does melt during reentry, the heat source modules are no longer constrained, and the heat scurce will disassemble as the result of aerodynamic forces. Thus, the heat source modules will have the desired low impact velocity.

The 36-inch-1ong heat source stack is supported by the generator housing at its ends. From a structural viewpoint, it would be desirable to provide additional lateral supports at intermediate points on the stack, but this would be undesirable from the thermal and mechanical design standpoint. The use of intermediate support.5 would require lengthening the generator to provide room for the supports, resulting in increased weight; and would result in increased heat losses and reduced efficlency. For these reasons, no intermediate heat source supports were used in Fairchild's Solar-Polar RTG design. 
Since the heat source stack is only supported at its ends, a high axial preload is required to keep the stack from falling apart under the influence of lateral launch loads. The analysis presented in Section III indicates that axial preloads of 12,0001 bs will be required to ensure stability during the shuttle launch, This is a much nore severe requirement than for the case of a monolithic heat source.

The RTG designer must solve the problem of providing axiaI and Iateral heat source supports, with very high axial preload5, while minimizing the miss of the structure and the resultant heat losses. The solution evolved in the Fairchild study is to use pyrolytic graphite (PG) buttons, backed by Belleville springs, at the four corners of each end of the heat. source. A total of $16 \mathrm{PG}$ buttons is used: eight for axial support, and eight for lateral support. The PG buttons penetrate the nultifoil thermal insulation, and the Belleville backup springs pres5 against the housing end caps.

The heat source support concept is illustrated by the exploded view in Figure 5 . The figure shows only one heat souroe module, but it is understood that this represents a stack of 18 such modules. As can be seen, there is a light-weight molybdenum cross-piece exbracing the four corners of each end module. At the extrenities of those cross-pieces are expanded seats, which mate with the pyrolytic graphite support buttons. They make it possible to locate the axial support buttons as far apart as possible, which reduces the preload required to hold the stack together during lateral launch loads. The cross-piece seats also serve to spread the load of the axial support buttons over a larger area, to reduce the compressive stress on the heat source blocks. Those blocks are made of a three-dimensional carbon-bonded csrbon-fiber structure, which has considerably less compressive strength than pyrolytic graphite.

Fig. 5 - HEAT SCURCE SUPPORTS

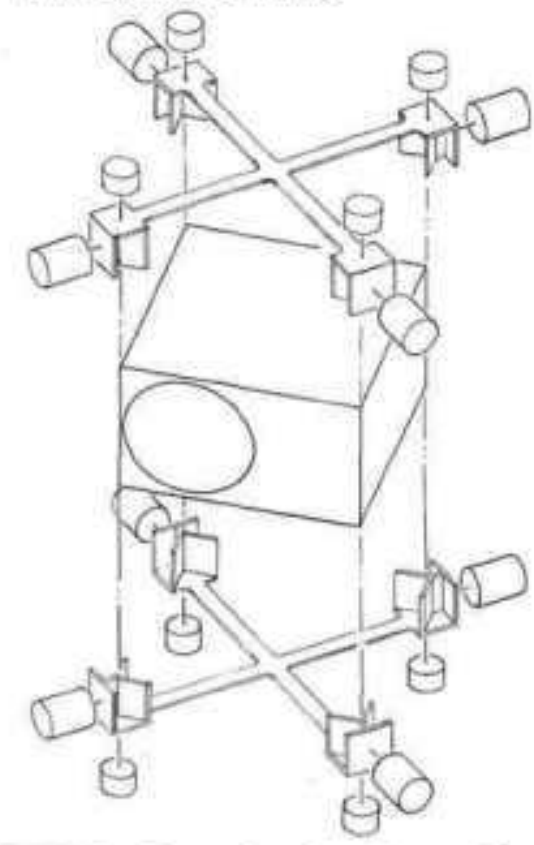

As seen in Figure 5, the side support-buttons. are mueh longer than the end buttons. This is necessary because the heat source's side insulation, which contains the thermoelements, is much thicker than the simple multifoil that insulates the ends of the heat source stack. Since the side PG buttons are Ionger, their diametor has also been increased ta proyide columnar stability. Because of their large cross-sectional area, the side buttons are conservatively designed, not only with respect to conpressive stress but also with respect to shenr stress.
Figure 6 shows the two molybdenum cros5-pieces and the sixteen PG buttons joined to the heat source stack. Only the end nodules of the stack are shown. Also shown are two graphite shear balls, which are present at each interface between adjacent modules: These balls, which are seated in henispheric cavities, provide a limited interlock function. They aid asseably and supplement friction in resisting lateral shear forces. But they contribute nothing to overcoming the tensile forces due to bending moments. Those tensile forces are resisted only by the compressive loads exerted by the axial PG buttons.

FIg. 8 - SPRING SUPPORTS AND SHEAR BALLS

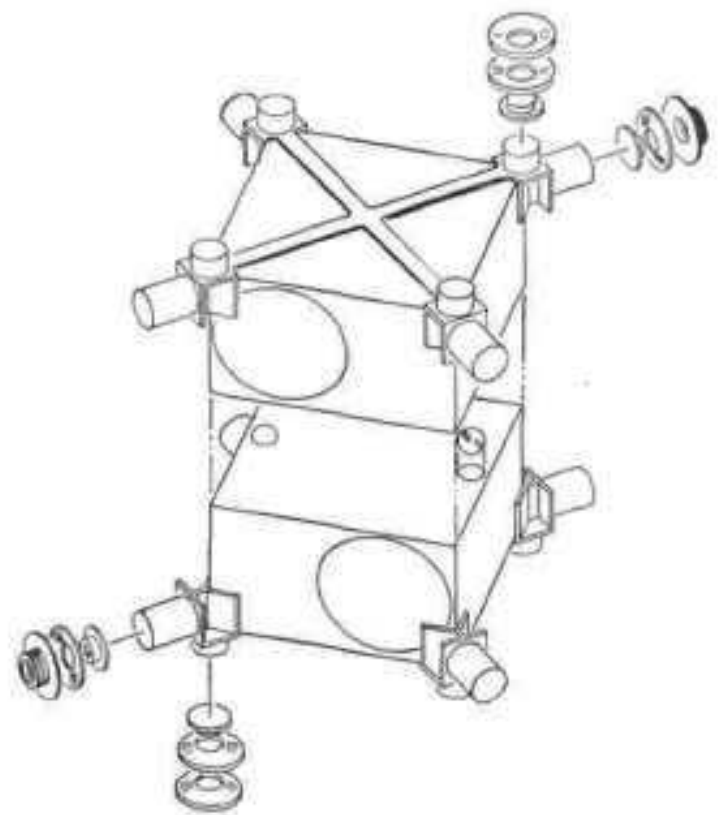

The conponents which spring-load the PG buttons are depicted in Figure 6, at two of the eight corners of the heat source stack. As shown, the side-load spring consists of a single Belleville washer. The end spring. which must furnish a much greater force, consists of pairs of two conical washers in parallel.

Belleville springs, which are very stiff but have a short stroke, are ideal for this application. Relatively little travel is required, because the spring loads are applied after the generator is assembled and the heat source and housing have had a chance to equilibrate at their norma1 temperatures. Thus, the springs do not need to compensate for dimensional tolerance stack-up. The only spring travel required is for the thermal changes which occur after the final preloads are applied at the launch site.

As seen in Figure 6 , at the inner end of each Belleville spring is a metal bushing, to distribute the spring force over the end face of the PG button. There is another bushing at the outer end of each spring. These transmit the axial and radial spring loads to the housing end caps.

The structural support and preload application scheme evolved in the Fairchild study is illustrated by the exploded view in Figure 7 and the assembled close-up view shown in Figure 8. The mult1-foil thermal insulation has been onitted in Figure 7 and earlier figures, to avoid obscuring other components.

The end cap design depicted at the top of Figure 7 is the result of extensive design iterations and NASTRAN analyses, to find i 10 w-woight solution for the high design loads. If made of berylliun, each end cap weighs less than 1 Ib. As can be seen, the end cap has four cup-shaped seats and 1oad-adjustment holes for the axial Belleville springs. These seats are combined within two vory stiff I-shaped cross-beams, to resist the bending moments produced by the axial spring forces. 


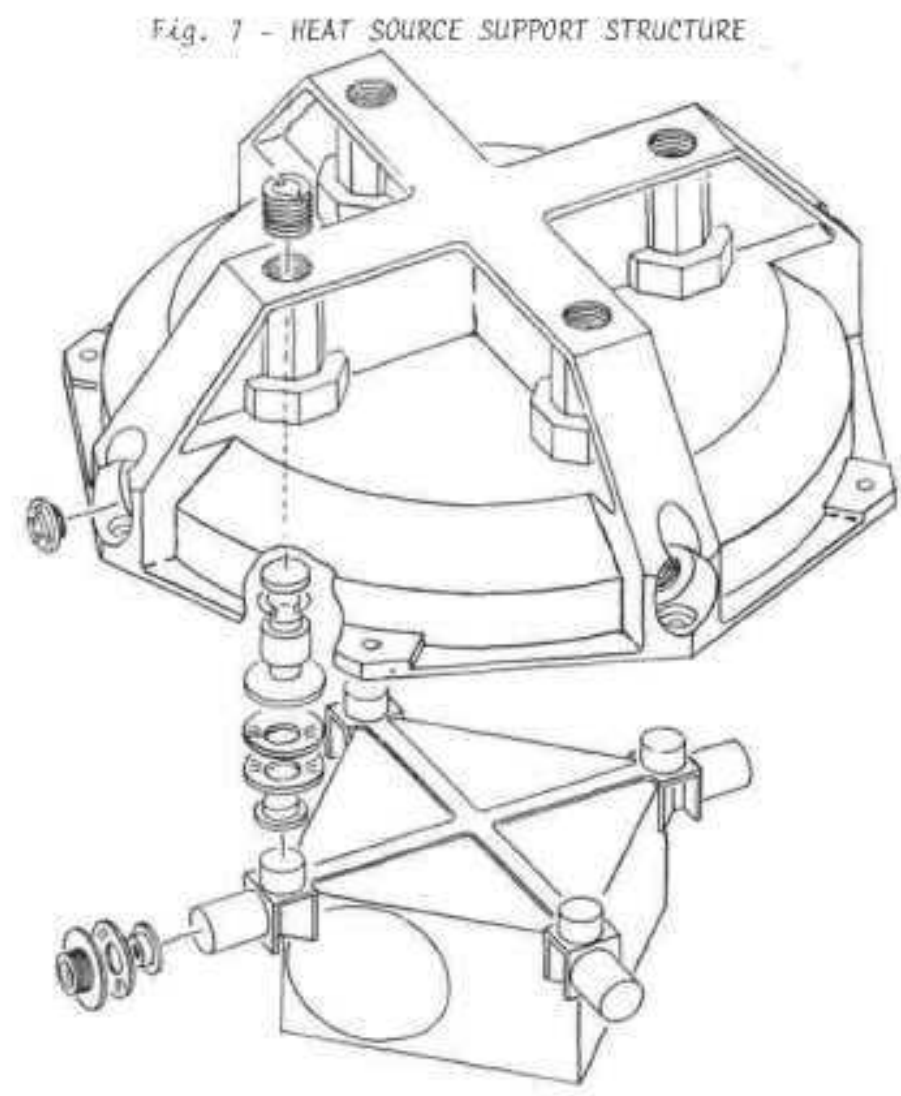

As illustrated in Figure 8, the end capst flanges are bolted to mating flanges on the RTG's cylindrical side wall. Gas-tight seals are obtained by means of metallic C-rings. This type of seal has been successfully used on earlier silicon-germanium RTGs (e,g., on the Voyager mission). Si-Ge thermcelements are designed to operate in vacuus, and sealing is only required for temporary retention of an inert cover gas. Once in orbit, the RTG is vented to space.

As shown in Figure 8 , the axial preloads can be adjusted to their desired values after final RTG assembly and thermal equilibration while maintaining the generator in a sealed condition. At each of the eight heat source corners, the desired load can be applled through the center of the lock screws, by

Fig. 8 - LOAD ADJUSTMENT SCHEME FOR SEALED RTG

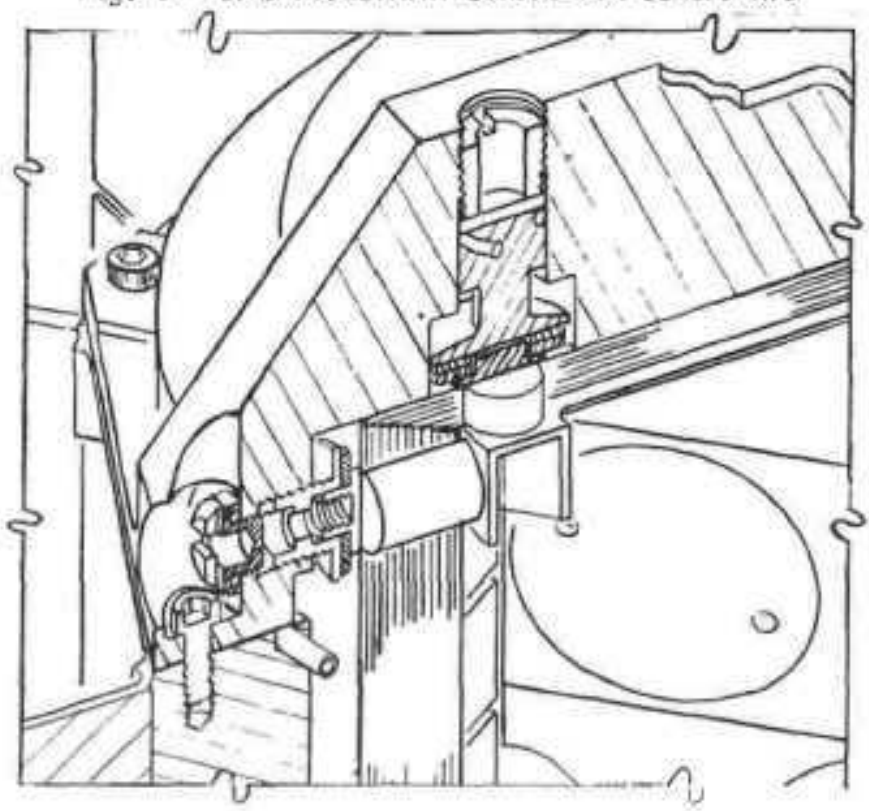

means of conpression fixtures using hydraulically or preumatically actuated pistons: (not shown). Thus, dimensional tolerance stack-ups--within linits--are automatically compensated at the tine the eight axial loads are applied.

After the desired axial preloads have been applied, the lock screws are tightened and the conpression fix. tures removed. Throughout this process, the seal at each sliding piston is mintained either by means of a pressure-loaded C-ring, as shown, or by means of a bollows. Since these operations can be carried out in an air environment, final spring force adjustment can be made at the launch site, shortly before launch. Thus, the very high spring forces need not be present during long-term storage, or during shipment to the launch site:

Sinilarly, the side spring forces can also be adjusted after RTG assembiy and thermal equilibration. As shown in Figure 8 , these forces are exerted against the rim of the end cap, at the ends of the two crossbeans. Fig. 9 - CUI-ANAY VIEW OF ASSEMBLED RTG

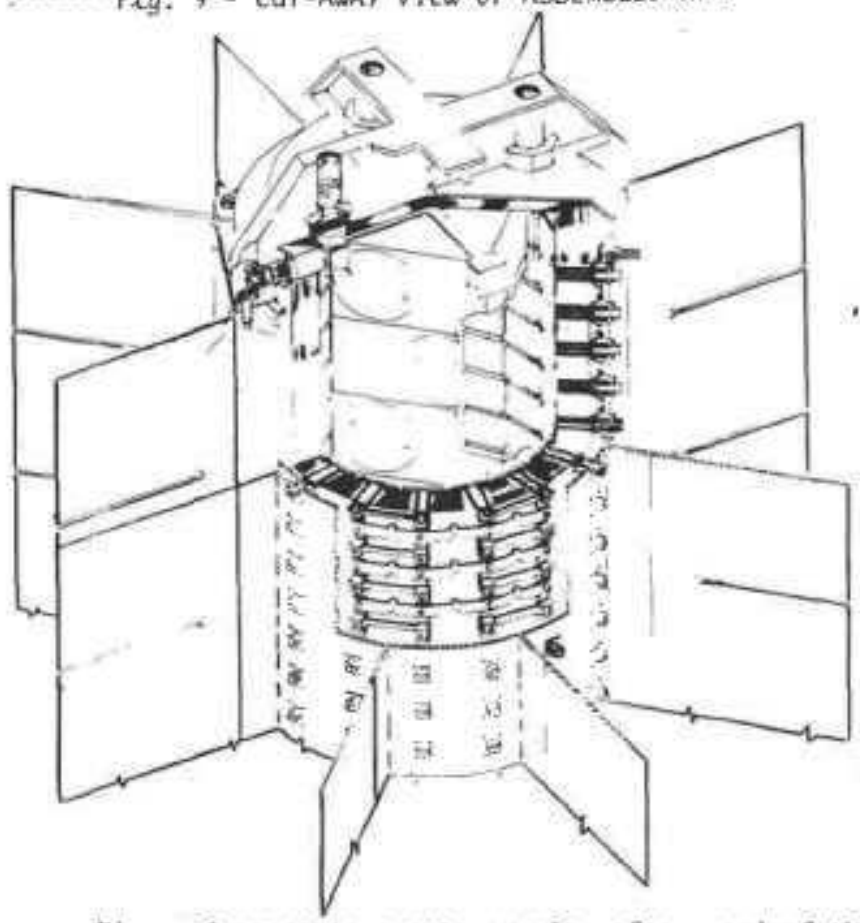

Figure 9 presents a cutaway view of one end of the assembled RTG. It shows the stacked heat source modules, their end support structure, and the end cap bolted to the housing flange, with the joint sealed by means of a C-ring. Part of the heat source stack has been cut away, to display the hot shoes at the opposite side of the converter cavity. The figure also shows. the 5 ide and end insulations. Both contain 60 layers of Mo multifoil, but the end insulation blanket is much thinner because it uses $2 \mathrm{rO}_{2}$ particles instead of quart? cloth to separate the foils.

As indicated, cach end of the heat source stack extends about one inch beyond the last ring of hot shoes. This is beneficial, because the heat from about half a module at each end of the heat source is available to compensate for thermal losses through the structural supports and end insulation. Thus, a more uniform axial temperature profile is obtained than if the hot shoes covered the entire length of the heat source stack.

As shown in Figure 9, the unicouples are cantilevered from the housing wall, to which they are attached by external nounting screws. As in the MHW RTG, the mourting holes are sealed by individual C-rings. The couples penetrate through the cylindrical insulation package; and the electrical connections are 
made on the outside of that package to form the desired sories-parallel network. Rivets are used to join the series and parallel copper connector straps.

Fig. 10 - ILLUSTRATIVE NETWORK ARRANGEMENTS

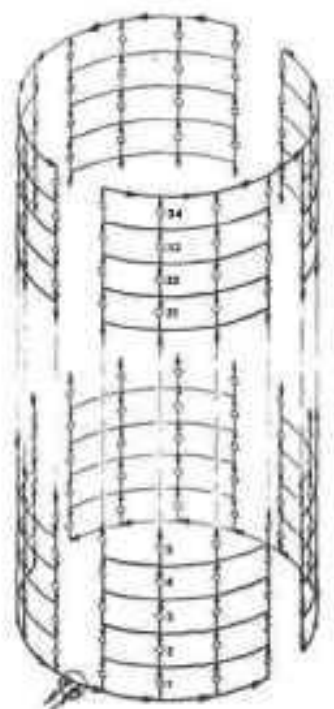

4 COUPLES IN PARALLEL

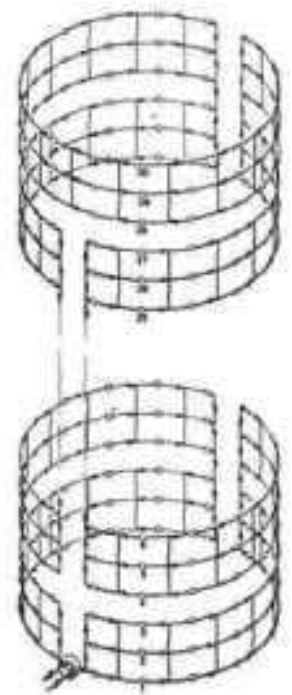

3 COUPLES IN PARALLEL
The parallel leads normally carry no current, but provide high reliability against open-circuit failure. The arrangement illustrated is for four couples in parallel. The corresponding circuit is depicted schematica11y in Figure 10, which al so shows an alternative circuit arrangement for three couples in paralle1. The effect of these alternatives on RTG weight will be examined in Section IV.

Figure 11 shows a view of the complete RTG, with typical dimensions in inches. There are eight radiating fins around the circumference of the generator housing. Thus, there is one fin for overy two columns Fig. It - TYPICAL RTG DTHENSTONS

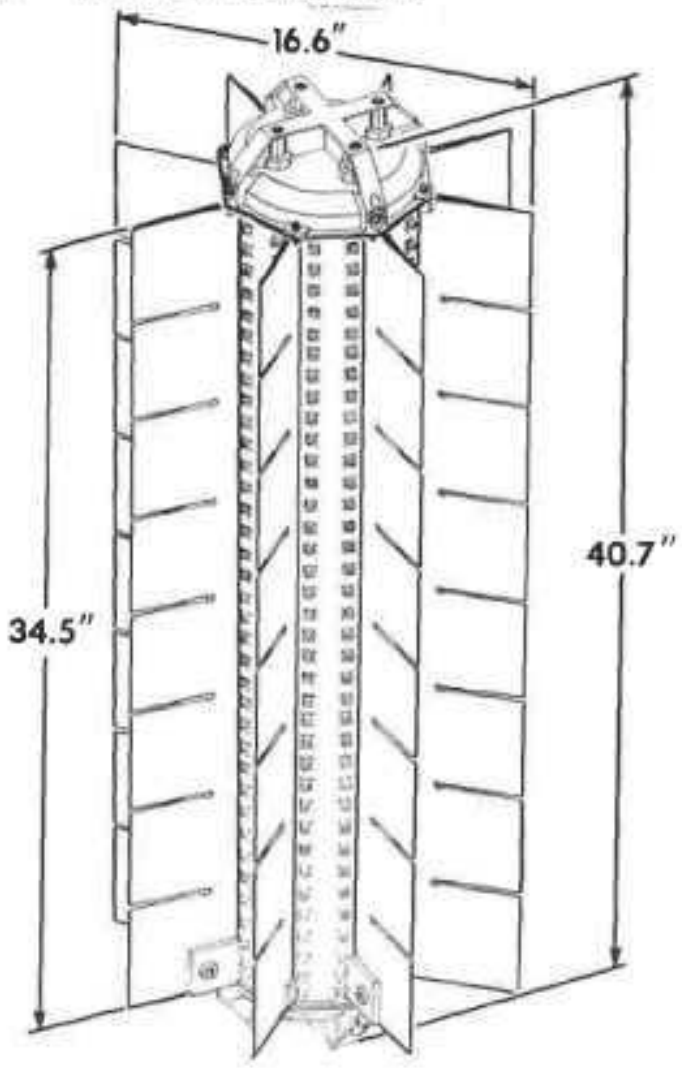

of unicouples. This reduces the heat rejection path length and the resultant teaperature drop to the fin root. The fins are made of beryllium, and have a trapezoidal cross-section. They are slotted at intervals of about 4 inches, to reduce thermal stresses. The outside of the housing and fins was assumed to be coated with iron titanate, which was used an the MHW RTG and has an emissivity of 0.85 .

As shown, the RTG has mounting pads and ba11 bushings at the bottom of alternate radiator fins, Thus, the generator is mounted to the spacecraft in a cantilevered fashion, with the RTG axis perpendicular to the spacecraft spin axis, as illustrated in Figure 12 for the NASN/JPL spacecraft.

Fig. 12 -

\section{RTG MOLANTED ON SPACECRAFT}

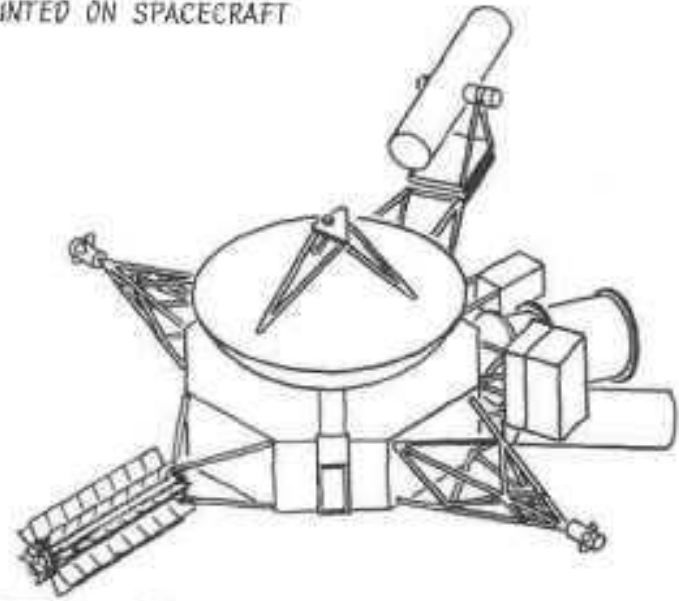

In a similar fashion, an identical RTG is nounted on the ESA spacecraft, as 11lustrated in Figure 13 , After the firing of the IUS upper stage is completed, the ESA spacecraft and its support structure separates from the NASA spacecraft, followed by separation of the NASA spacecraft from the IUS.

Fig. 13 - SPACECRAFTS WTTH RTGS ON TUS

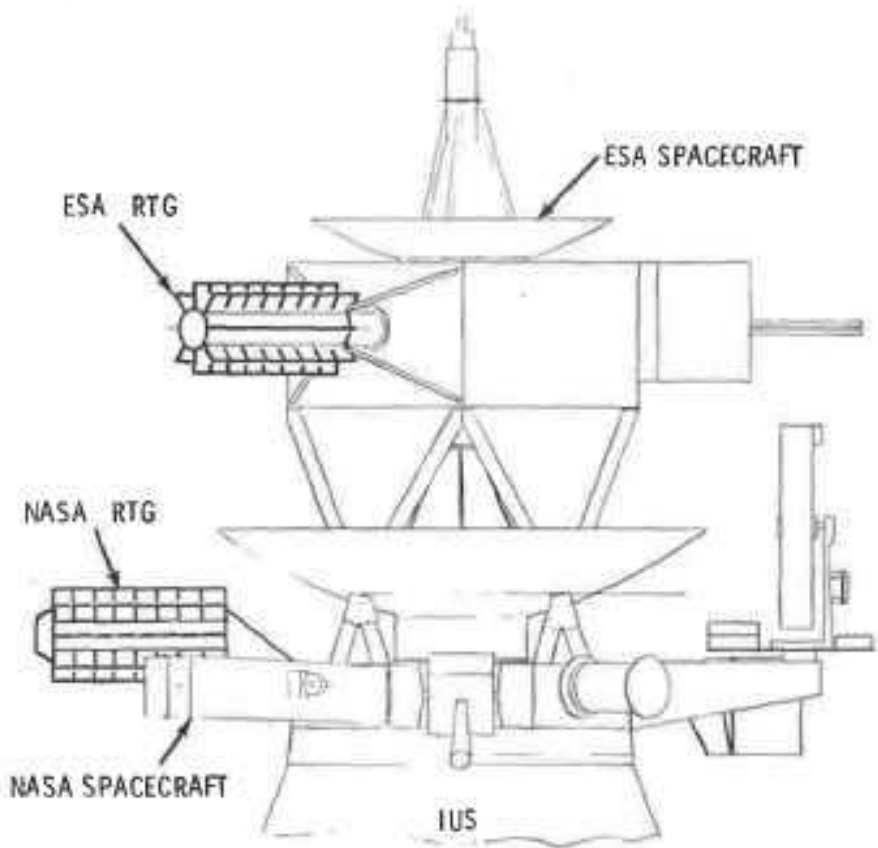

As depicted in Figure 14, the whole assembiy fits within the shuttle bay's payload envolope, with each RTG mounted to its spacecraft in its fixed flight position. Therefore, mechanisms for RTG deployment after launch will not be needed. 
Fig. 14 - RTGS, SPACECRAFT, AND IUS IN SHUTTLE BAY

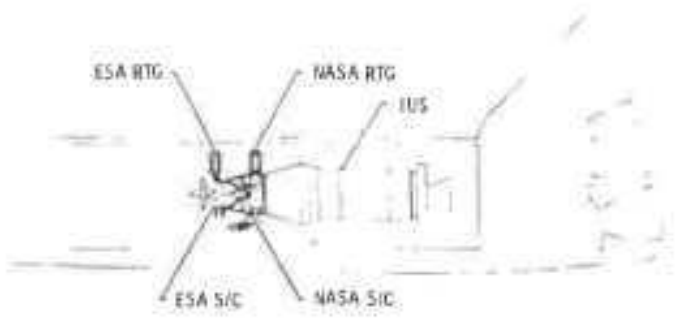

While the RTGs are within the shuttle bay, auxiliary cooling must be provided for then, because of their high heat rejection rate. Cooling will be by a circulating water loop, delivering the reject heat to a water boiler which discharges the resultant steam outside the shuttle. The RTGS cauld be cooled directly, by water tubes bonded to their fin roots. This would require disconnection of coolant supply lines in earth orbit. To avoid that complication, the RTGs could be cooled by air convection and radiation to a separate water-cooled shroud, as fllustrated in Figure 15.

Fig. 15 - COOLING ARRANGEMENT FOR RTG IN SHIITTLE BAY

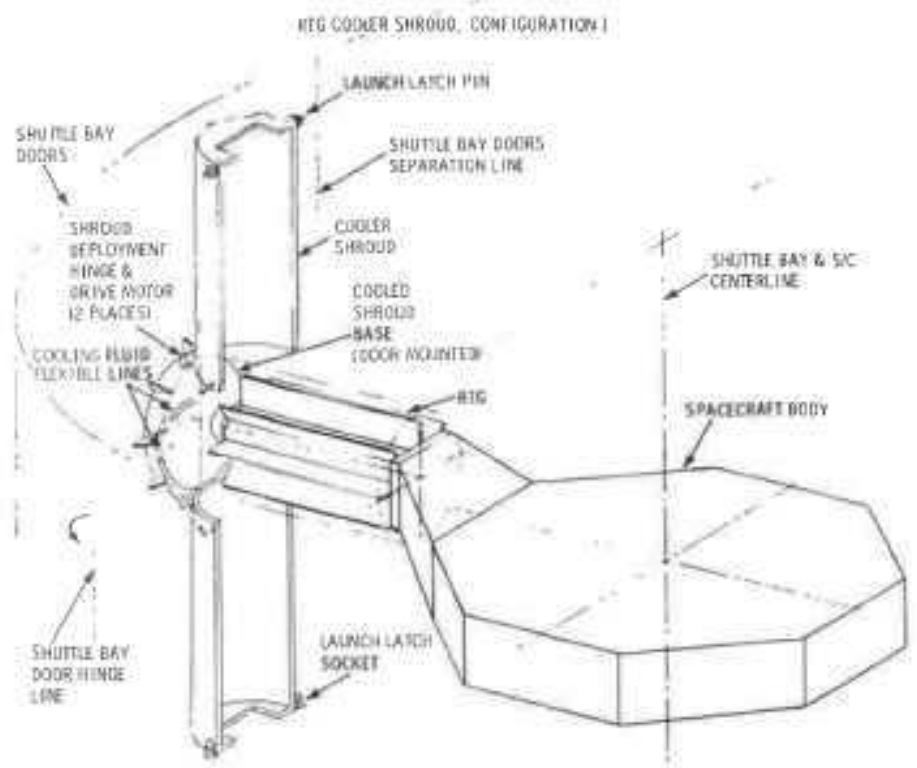

With this arrangement, there is no need for breaking coolant lines in orbit, and no danger of coolant. droplets lodging on optical or other sensor5. The cooling shroud opens in a clamshell fashion, permitting unobstructed removal of the IUS/spacocraft assembly, and its deployment outside the shuttle.

\section{IJ1. STRUCTURAL ANALYSIS}

While the structural adequacy of the heat source support scheme described in Section 11 under anticipated dynamic loads had been confirmed by proliminary static anaiysis, it was decided to verify it with a detsiled dynamic analysis, using prescribed shutt le and IUS launch loads. For this purpose, a finite-element model of the RTG for NASTRAN $\{4,5\}$ analysis was constructed. Figure 16 shows a structural oodel of the RTG end cap. including cross-beams and flanges. The heavy dots designated by upwards and outwards arrows represent the points at which the axial and radial spring forces are applied to the end cap; and those deslgnated by downwards atrows show where the end cap is attached to the housing flatige.
Fig. Io - STRUCTURAL-ANALYSIS MODEL OF RTG END CAP

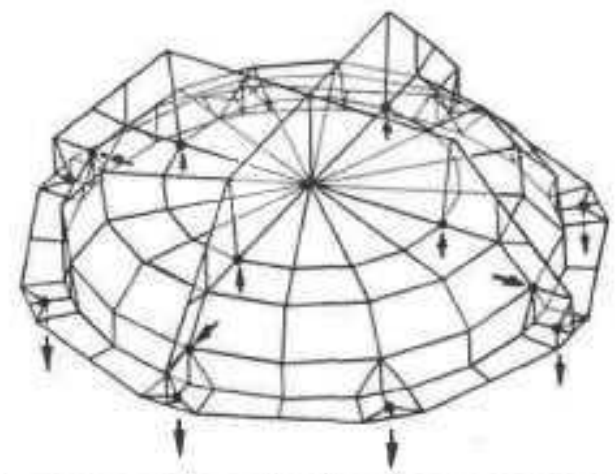

To save computer time in the subsequent analyses, a simplified model of an end cap with equivalent structural characteristics was constructed. The tro cross-beams are represented by bars of equivalent stiffness. The model is shown at the top and bottom of Figure 17 , which also shows the finite-element models of the RTG's other structural components: the heat source stack, its support springs, and the penerator housing;

Fig. 17 - STRUCTURAL-ANALYSIS MODEL OF RTG
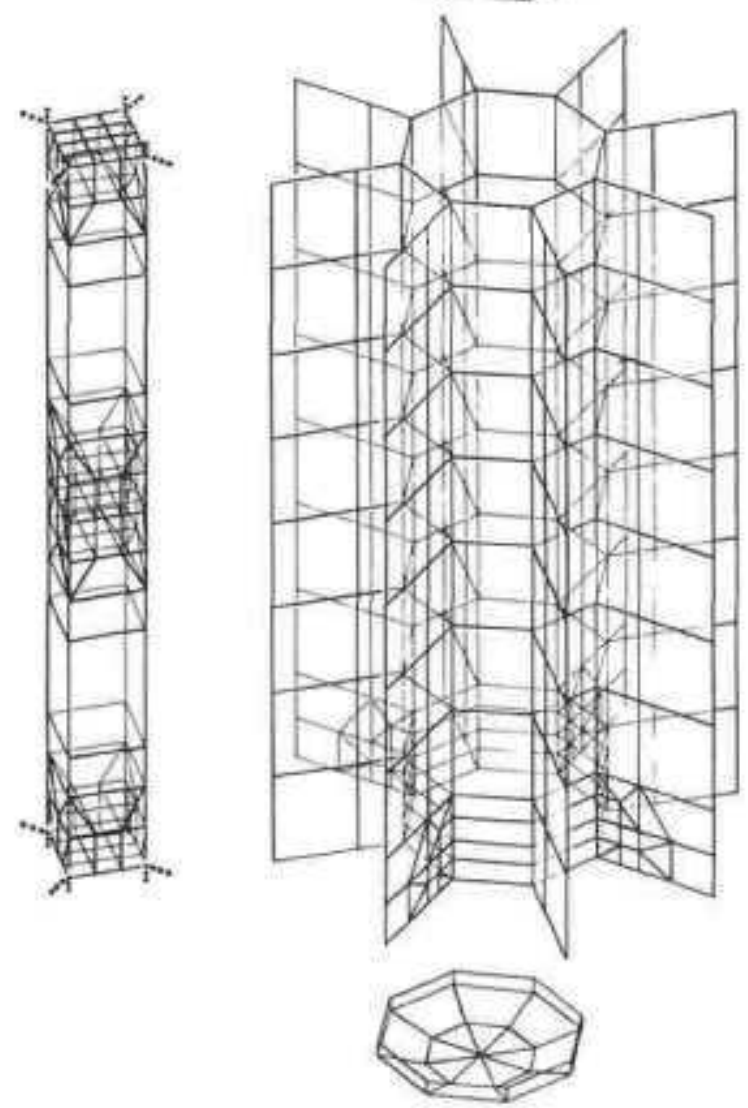

The heat source stach depleted consists of 18 modules; which are nodeled as hollow boxes with six face plates. As can be seck, the six middle modules und the three at each end of the stach are modeled individunlly. The orher sis have heen combined into tho groups of three, A more detailed model is used 
at the stack's ends and center, where the bending moments due to lateral loads are greatest. Sinflarly, in the RTG housing model, a finer structure is used at the bottom of every other fin, where the cantilevered RTG is attached to the spacecraft support structure. At each corner of the heat source stack are short lines of heavy dots, representing the axial and radial support springs.

Figure 18 shows the top end of the combined analytical model, which represents the structural relationship of tho heat source stack, support springs, end caps, and housing in the asseabled RTG. Altogether, the RFG model consists of 560 grid points, 816 element.5. 3088 static degrees of freedon, and 264 dymanic degrees of freedom.

Fig. is

- TOP END OF STRUCTURAL-ANALYSIS MODEL OF ASSEMBLED RTE

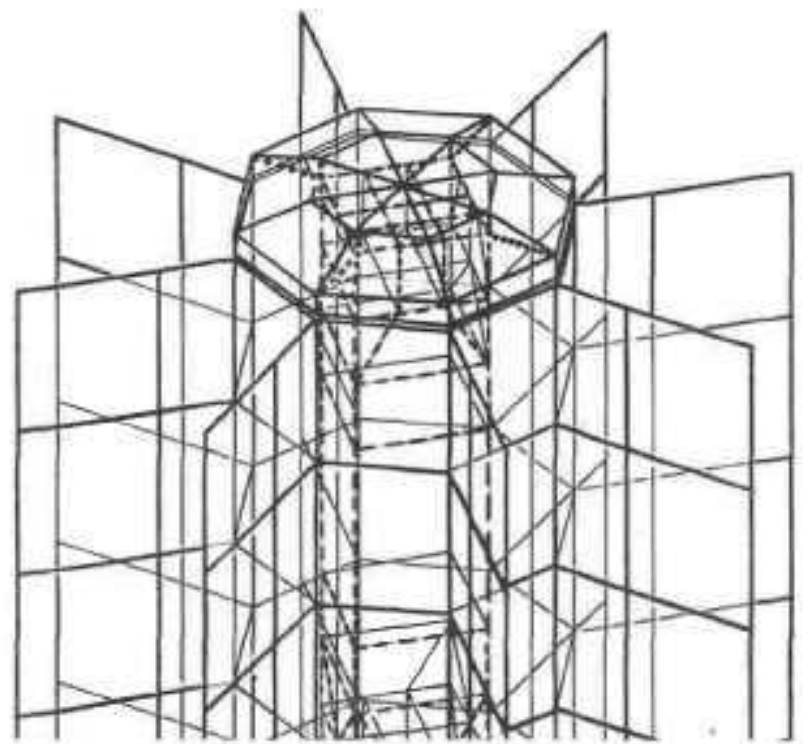

Finally, Figure 19 shows the model of a representative ISPM spacecraft with a cantilevered RTG attached to its support structure. Such a combined nodel can be exercised by applying the anticipated axial and lateral launch loads at the IUS/spacecraft interface, to determine the various characteristic frequencies of the system, the loads transnitted to the RTG, and the resultant stresses and displacements. The avallability of a structural model of the spacecraft makes it unnecessary to guess at the attenuation or amplification fictors between the IUS and the RTC. Note that the quadrapod structure extending above the spacecraft supports the ESA spacecraft. A duplicate RTG is mounted on that spacecraft and a similar analys is would have to be performed in order to determine the loads on the RTG motunted on that spacecraft.

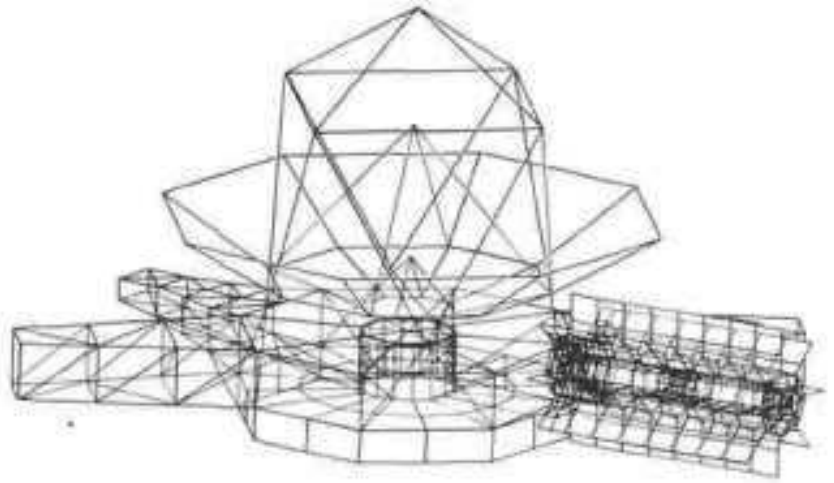

Fig. 19-STRUCTLRAL-ANALYSIS MODEL OF RTG ON SPACECRAFT
The structural evaluation of the RTG examined three critical fIight conditions: the shuttle launch, latuch, including the effect of the 70-RPM 3rd-stage spin of the IUS, The prescribed spacecraft-1evel quasi-static design loads, beforo safety factors, are summarized in Table 1 , where the $x$-direction denotes the longitudinal axis of the orbiter, the IUS, and the spacecraft. The RTG axis lies in the orbiter's yz-plane, close to the $z$-direction. Therefore, the static and dyramic 8 -loads in the $x$ and $y$ directions will produce bending of the heat source stack.

Table I. INPUTS FROW IUS TO ISPN SPACECRAFT (X, Y, Z Directions Refer To Shuttle Axes)

\begin{tabular}{|l|c|c|c|}
\hline EVENT & $\begin{array}{c}\text { LOAD } \\
\text { DIRECTION }\end{array}$ & $\begin{array}{c}\text { STEADY } \\
\text { G-LOAD }\end{array}$ & $\begin{array}{c}\text { DYNAMIC } \\
\text { G-LOAD }\end{array}$ \\
\hline SHUTTUE & $X$ & -1.6 & +2.5 \\
LAUNCH & $Z$ & 0.0 & \pm 1.9 \\
& $Z$ & 0.0 & \pm 6.0 \\
\hline & $X$ & 0.0 & \pm 0.7 \\
SHUTTLE & $Y$ & 0.0 & \pm 1.0 \\
LANDING & $Z$ & +1.0 & \pm 7.7 \\
\hline & $X$ & -5.5 & \pm 1.5 \\
IUS & $Y$ & 0.0 & \pm 1.0 \\
LAUNCH & $Z$ & 0.0 & \pm 1.0 \\
\hline
\end{tabular}

Table II presents the results of a dynamic response analysis, both random and sinusoidal, issuming. 5\% structural damping. The analysis used a detailed mode1 of the ISFM spacecraft and the RTG support structure, and a concentrated RTG mass, located 22.5 degrees off the orbiter's $\mathrm{z}$-axis. The table shows the three resonant frequencies resulting in vibrational input 5 to the RTG, the resultant tri-axial g-load amplification factors at the RTG, as well as the overall responses to randon vibration (using the 8.4 GRMS input predicted by Boeing).

Table II. DYNAMIC RESPONSE OF CONCENTRATED RTG MASS DUE TO SINUSOIDAL AND RANDOM INRTSS AT IUS/SC INTERFACE (X, Y, Z Directions Reler To Shuttle Axes)

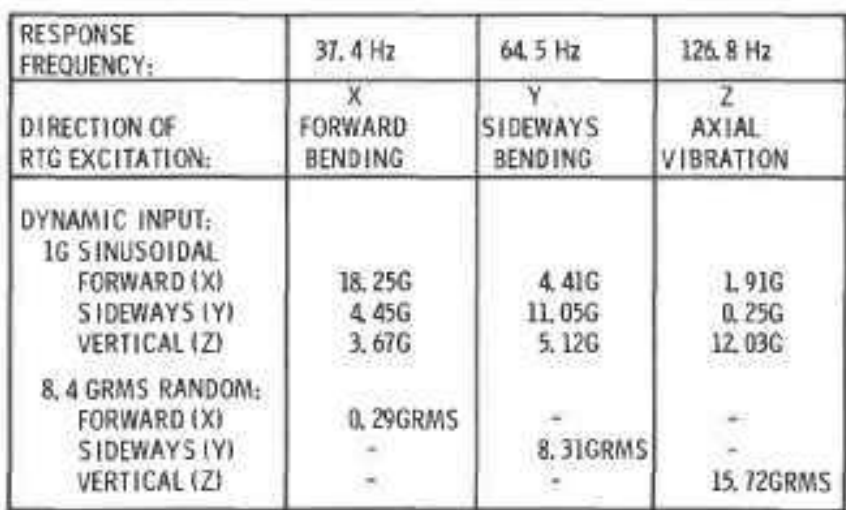

JPL has proposed an input Ievel of 1.5G for the simusoidal tests, subject to specified load limits which are a function of spacecraft appendage weight. Considering the RTG as a 100 ib appondage with 2 s structural damping, the specified test load 1 imit is 256 , which would be achieved by notching tho input levels in the sinusoldat test of the spacecraft. For a safety factor of 1,4 , this results in an ultimate design load of 356 .

The above launch loads, test loads, amplification Factors, together with safety factors of 1.4 for the shuttle launch and 1.25 for the HUS free flight, result in the design loads shown in Table III 


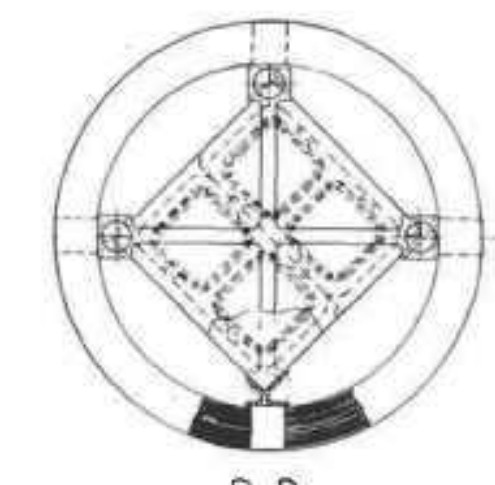

$\frac{B \cdot B}{\substack{n-1 \\ \text { sat }}}$

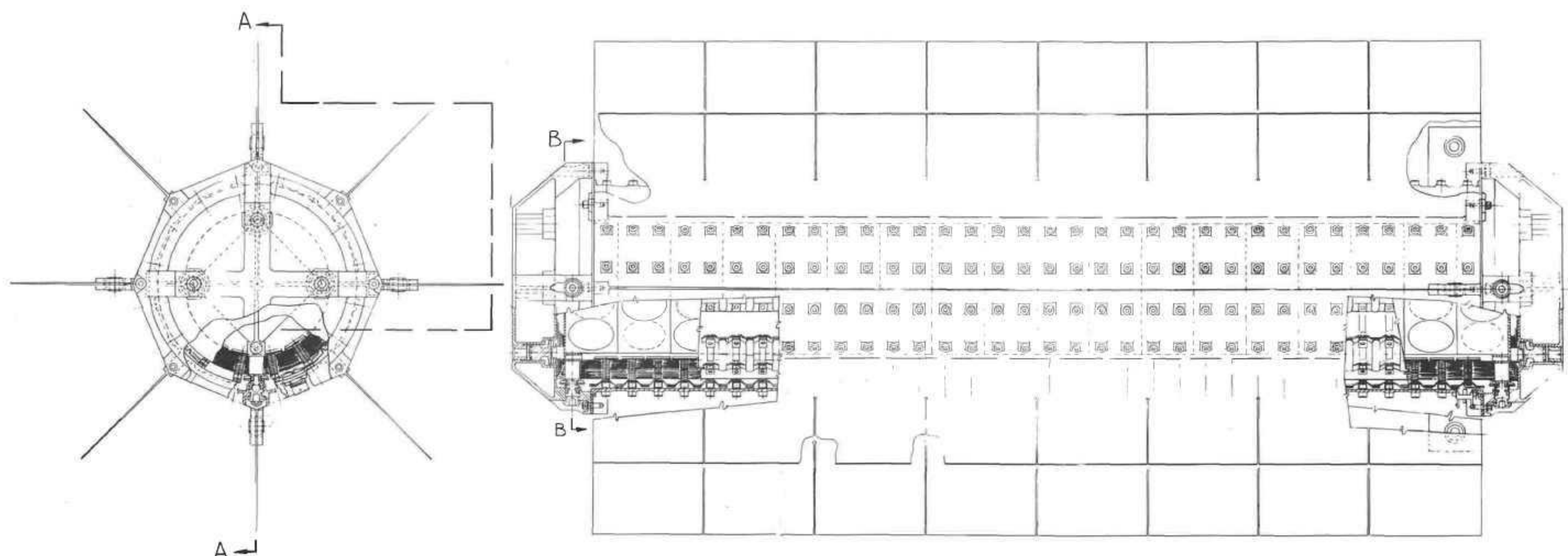


Table III. ULTIMGATE G-LOAD INPUTS IO RTG Uincluding Safety Factorst

\begin{tabular}{|c|c|c|}
\hline \multirow{2}{*}{ EVENT } & \multicolumn{2}{|c|}{ DIRECTHON OF LOAD ON RTG } \\
\hline & LAIERAL & $A \times \mid A L$ \\
\hline $\begin{array}{l}\text { FLIGHT PHASE- } \\
\text { SHUTRE LAUNCH } \\
\text { SHUTHE LANDING } \\
\text { IUS LAUNCH" }\end{array}$ & $\begin{array}{r}10.2 \\
12.2 \\
8.8\end{array}$ & $\begin{array}{r}2.7 \\
1.4 \\
13.1\end{array}$ \\
\hline $\begin{array}{l}\text { SINE TEST (1. SG) } \\
\text { X (FORWARD) } \\
\text { Y (SICEWAYS) } \\
\text { ZIVERTICAL) }\end{array}$ & $\begin{array}{l}38.5 \\
23.2 \\
10.8\end{array}$ & $\begin{array}{r}4.0 \\
0.5 \\
25.3\end{array}$ \\
\hline
\end{tabular}

INCLUDING EFHECT OF 70 RPA SPIN

As can be seen, the dynamic test conditions are much more severe than the anticipated flight conditions It wis therefore concluced that these should govern the initia1 RTG design load criteria. This conclusion must be vorified by the dynamic analysis of the combined snacecraft and FTG model shown in Figure 19. Based on the results tabulated above, the three uitimate design load criteria shown in Table IV were selected for the structural analysis of the RTG:

Table IV.

\begin{tabular}{|c|}
\hline ULTIMATE DESIGN LOAD CRITERIA FOR RIG \\
\hline - 40 L LATERAL PLUS III AXIAL AT SHUTHLE LAUTACH TEMPERATURES \\
\hline 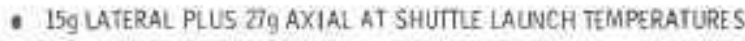 \\
\hline - IEQ LAJERAL PLUS $20 \mathrm{~g}$ AXIAL AT I US LAUNCH TEMPERATURES \\
\hline
\end{tabular}

The last design criterion is 505 higher than the predicted Jus launch loads, since the required transient response antalysis has not been done yet. Although the last load combination is less severe than the first two, it sust be examined separately for two reasons: The RTG housing is warmer (and therefore weaker) during launch, because of less effective cooling; and the axial spring forces during the IUS lauch are substantially lower, due to the differeatial theral 1 expansion effects discussed later.

To determine the axial spring forces required to hold the heat source together during the shuttle launch, the detailed structural model of the RTC described earlier was subjected to a combined quasistatic load of $40 \mathrm{~g}$ lateral and $11 \mathrm{~g}$ axial. The results. of the NASTRAN analysis indicated that, with a load of 500 lbs on each side spring, a load of 2840 lbs on each axisl spring is required to maintain a positive compressive stress tit bil interface locations, to ensure that the module stack will not fall apart under the bending monents produced by the lateral load. Thus, the analysis indicates that a combined axial spring load of about 12,000 lbs is required to survive: the shuttle launch; and a similar analysis showed that a combined spring load of about 4,000 tbs is required to survive the IUS launch loads.

The required spring constant of the axial springs is determined by differential thermal expansion effects Because of RTG temperature changes between the shuttle launch and the IUS launch, there is a change in the relative length of the heat source and housing. As will be shown, these thermal expansions have the effect of increasing the axial spring lengths and relaxing the spring forces. Therefore, the axial spring constants must be low enough to retain sufficient axial load (4000 lts) for surviving the IUS launch.

The housing terperature depends primarily on the cooling method exployed. If water is pumped through coolsnt tubes attached to the fin roots, the housing temperature will be around $100^{\circ} \mathrm{C}$. If the heat trans- fex from housing is by natural convoction of ambient air (0.g., to a water-cooled shroudl, a temperature of about $180^{\circ} \mathrm{C}$ is expected. And if the housing is in a vacuum, and cooled only by radiation, its temperature is around $300^{\circ} \mathrm{C}$.

The temperature difference between the housing and the heat source depends primarily on the cover gas inside the RTG. Cover gas will be used to keep the hoat source and the thernoelectrics cool during prolaunch storage and shipment, to miniske any degradation; and to prevent the infusion of oxygen when the RTG is surrounded by atmospheric atr.

Table $V$ presents approximate values of the heat source surface temperature for three different cooling methods and five different cover gases (plus vacuum? -

Table V. EFFCT OF COOLING METHOD AND COVER GAS ON H.S. IEMPERATURES

\begin{tabular}{|c|c|c|c|c|}
\hline \multicolumn{2}{|c|}{ HOUSING COOLEO BY } & $\begin{array}{c}\text { FORCED } \\
\text { CONVECIION }\end{array}$ & $\begin{array}{l}\text { NATURAL } \\
\text { CONVECTION }\end{array}$ & RADIATION \\
\hline \multicolumn{2}{|c|}{$\begin{array}{l}\text { COOLANT } \\
\text { HOUSING TEMPERATURE }\end{array}$} & $\begin{array}{l}\text { WATER } \\
100^{\circ} \mathrm{C}\end{array}$ & $\begin{array}{l}\text { AIR } \\
180^{\circ} \mathrm{C}\end{array}$ & $\begin{array}{l}\text { VACLULM } \\
300^{\circ} \mathrm{C}\end{array}$ \\
\hline \multicolumn{2}{|c|}{ HEAT SOURCE TEMP. ${ }^{\circ} \mathrm{C}$} & & & \\
\hline 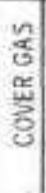 & $\begin{array}{l}\text { HELIUM } \\
\text { NEON } \\
\text { ARGON } \\
\text { KRYPTON } \\
\text { XENON } \\
\text { VACUUM }\end{array}$ & $\begin{array}{l}604 \\
750 \\
836 \\
865 \\
881 \\
907\end{array}$ & $\begin{array}{l}656 \\
811 \\
899 \\
928 \\
944 \\
971\end{array}$ & $\begin{array}{l}745 \\
908 \\
996 \\
1025 \\
1041 \\
1067\end{array}$ \\
\hline
\end{tabular}

The scenario which the RTG will experience fron assenbly through launch has not been fully defined. but some general principles can be discerned. After the RTG has been assembied and acceptance tested, it may be stored in a dornant condition for about a year. During this period, the RTG nay be filled with helium and water cooled, to lower the heat source temperature in order to minimize grain growth of the iridium fuel capsules and silicon sublimation from the thermoeloctric elements. But during subsequent shipment to the launch site, natural-convection air cooling seems preferable to water cooling, to reducc the complexity of the required ground support equipment.

It is probable that the least conductive inert gas (xenon) will be used during the shuttle launch. to maximize the electrical power availabie to the autonomous spacecraft. The lUS launch will take place after the cover gas has boon vented, and with the RTG cooled only by radiation.

The temperature variations shown in Table charge the relative lengths of the heat source and the RTG housing. Although the heat source can experience very large temperature changes, the thermal expansion coefficient of 30 graphite is extrencly low, The dominant length changes will be in the housing. because of the much higher expansion coefficient of beryllium or aluminum. The difference in the iength changes between the heat source and the bousing must be compensated by a similar length change in the axial springs.

For example, consider the case where the RTG is water-cooled and filled with xenon during the shuttle launch, and radiation-cooled and evacuated before the IUS launch. This raises the tenperature of the beryllium housing from $100^{\circ} \mathrm{C}$ to $300^{\circ} \mathrm{C}$, causing a length increase of 0.092 inch; and raises the heat source temperaturo fron $881^{\circ} \mathrm{C}$ to $1067^{\circ} \mathrm{C}$, causing a length increase of 0.018 inch. Thus, there is a net differential thermal prowth of 0.074 inch, which must be compensated by a reduction in the axial spring forces. 
To provide retention of adequate spring load during the 105 launch, a spring constant of 56,500 lbs/inch per axial spring was selected. Analysis (which also took account of the effective spring constants of the heat source stack, the housing, and the end eaps? indicated that the thermat expansion effects cited above will reduce the corbined axial spring force from 12,000 lbs to 5348 bs. This is: appreciably highor than the 4000 Ib axial Joad which the NASTRAN aralysis had indicated as required to. hold the heat source stack together during the lus launch.

The solected spring constant value of 56,500 lbs/inch per axial spring was used in a NASTRAN modal anglysis to determine the resonan frequencies of the RTG. Those frequencies, together with the previously detormined resonant frequencies of the ISPM spacecraft, are 1 isted and identified in Table VI.

Table VI.

SPACECRAFT AND RTG RESONANCES YIELDED EY MODAL ANAIYSIS

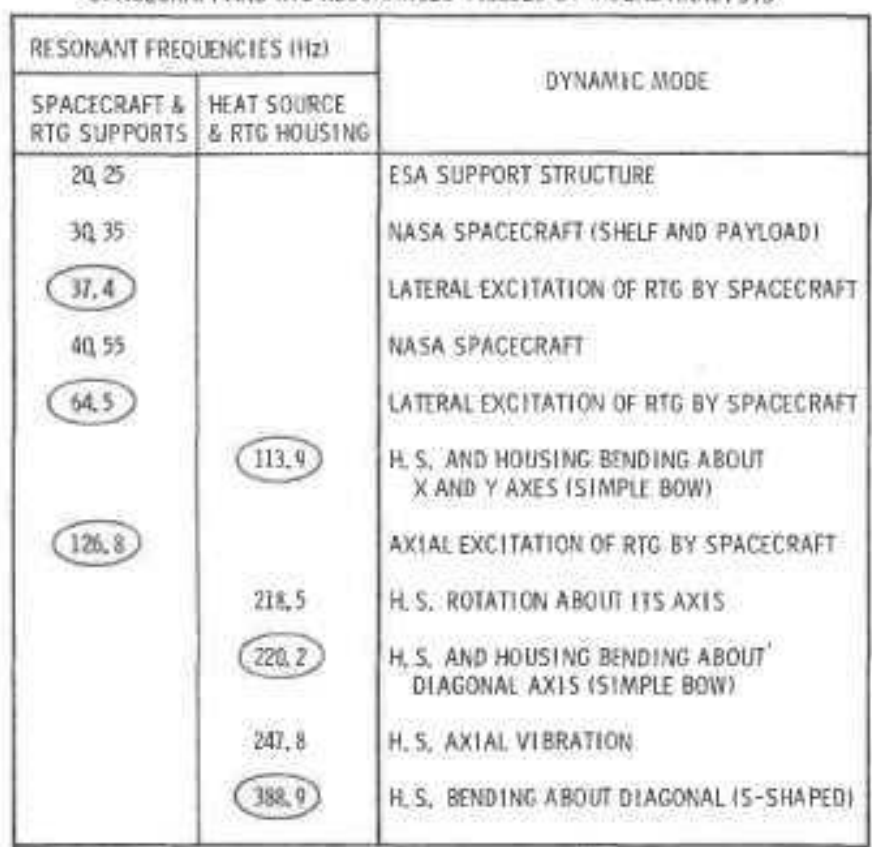
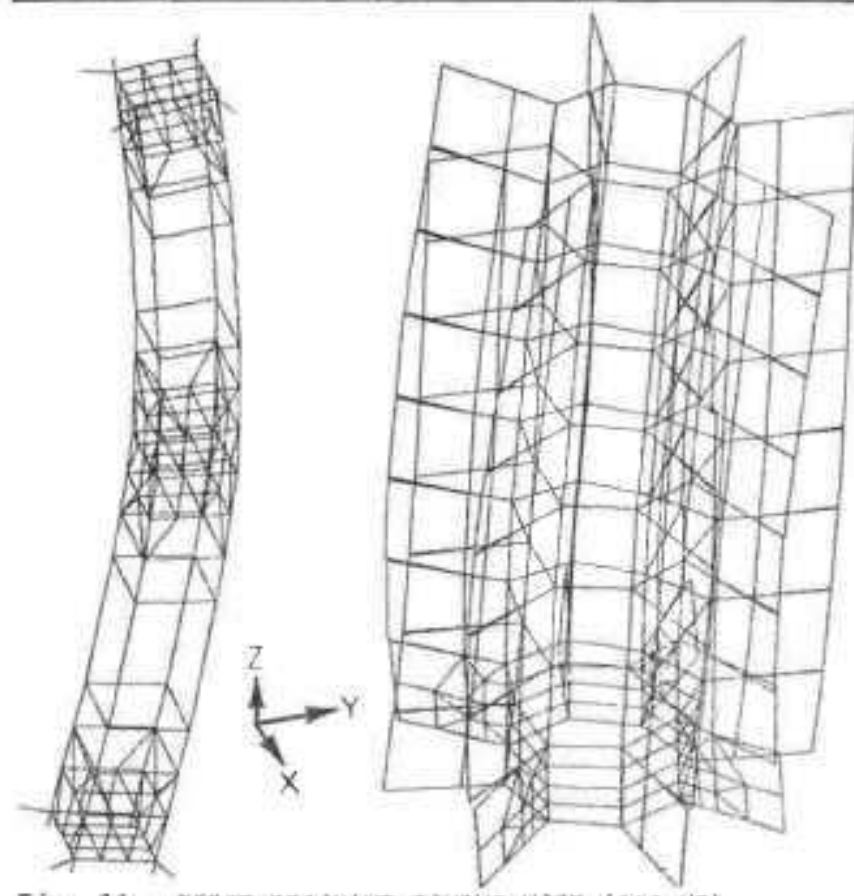

Fig, 20 - FIRST RESONANT BOWING MODE (113 $\mathrm{HZ}$ )
Fig. 21 - SECOND RESONANT BOWTNG MODE [220 HZ]
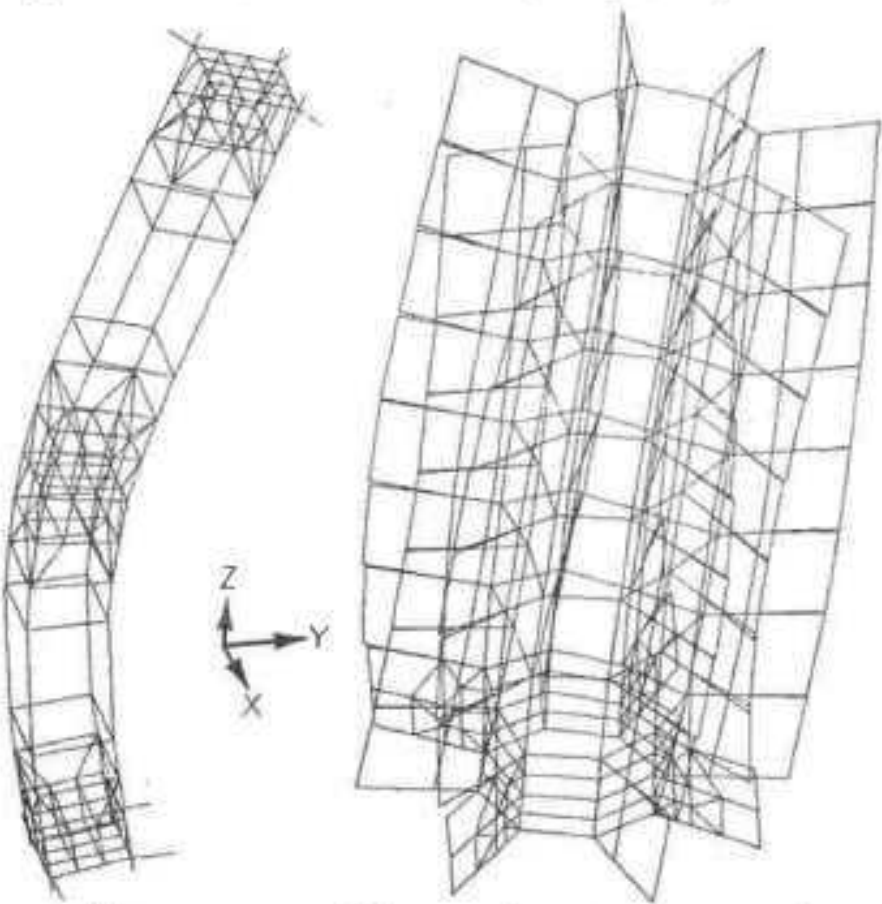

The resonances which are of greatest concern in evaluating the viability of the heat source support scheme are those which represent bowing of the heat source stack, since they could lead to heat source disassombly and RTG destruction. The three lowest. such resonances and the resultant RTG deformations (greatly exaggerated to enhance visibility) are depicted in the NASFRAN-genorated grid plots shown in Fipures 20, 21, and 22.

As can be seen, none of these resonances (113, 220,389 hertz), nor any of the others listed in Table VI, are near the three resonant frequencies ( 37,65 , and 127 hertz) at which the spacecraft excites the RTG. The RTG resonances are sufficienty high such that the dynanic response of the RTC to low frequency excitation should be very ninimal.
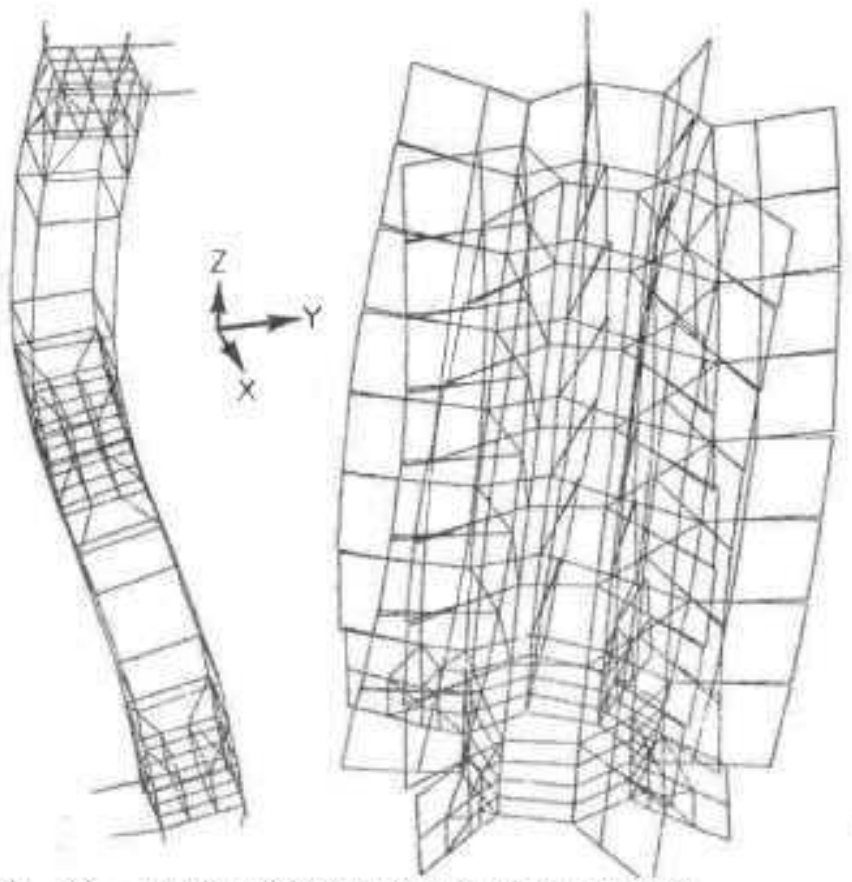

Fig. 22 - THIRO RESONANT BOWING MODE (389 HZ) 
The stresses of various RTG nembers under the thrce critical design load conditions presented earlier are sumnarized in Table: VI, which also gives the allowahle stresses for each material. The properties of the 30 graphite 15 ed here are based on the latest avitlable dista conpilation, and an estimate of 0.3 for Poisson's ratio. Additional mechanicalproperty tests of a complete acroshell module would be highly desirable.

Table VI

SUMWARY OF CRITICAL RTG STRESSES (PSI)

\begin{tabular}{|c|c|c|c|c|c|}
\hline \multirow{2}{*}{\multicolumn{3}{|c|}{$\begin{array}{l}\text { FLIGHT PHASE } \\
\text { C-LOADS: } \\
\text { LATERAL LOAD } \\
\text { AXIAL LOAD }\end{array}$}} & \multicolumn{2}{|c|}{ SHUTLI } & 105 \\
\hline & & & $\begin{array}{l}606 \\
116\end{array}$ & $\begin{array}{l}156 \\
2 \pi G\end{array}$ & $\begin{array}{l}146 \\
206\end{array}$ \\
\hline \multicolumn{3}{|l|}{$\begin{array}{l}\text { TEMPERATURE Q } \\
\text { HEAT SOLRCE } \\
\text { HOUSING: }\end{array}$} & $\begin{array}{l}8 \% 1 \\
100\end{array}$ & 881 & $\begin{array}{r}1067 \\
300\end{array}$ \\
\hline \multicolumn{3}{|c|}{$\begin{array}{l}\text { SPRING LOAQ, LDS } \\
\text { AXIAL SPRING } \\
\text { SIDC SPRING }\end{array}$} & $\frac{2850}{510}$ & $\begin{array}{r}260 \\
510\end{array}$ & $\begin{array}{r}1289 \\
519\end{array}$ \\
\hline HTC COMPONENT: & TYPE OF STRESS & ALIOWAELI & \multicolumn{3}{|c|}{ COMPUTED STRESS } \\
\hline ENo BUtroN & CONPRESSIVE & 6200 & 8.380 & $7, \mathrm{kn}$ & 3,856 \\
\hline SIDC ButTCN & CONPRESSIVE & $62 \times 0$ & 2454 & 1,795 & 1720 \\
\hline BNOCAP & TENSILE & 1800 & $16, \pi)$ & 15,002 & 800 \\
\hline K.5. ENO & $\begin{array}{l}\text { CONPRESSIVE } \\
\text { SHEAR }\end{array}$ & $\begin{array}{l}15,000 \\
3,000\end{array}$ & $\begin{array}{r}11,392 \\
5,649\end{array}$ & $\begin{array}{l}3646 \\
\angle 604\end{array}$ & $\begin{array}{l}3,201 \\
2,632\end{array}$ \\
\hline KS. MIDDLE & $\begin{array}{l}\text { CONPRESSIVE } \\
\text { SHEAR. }\end{array}$ & $\begin{array}{r}15,000 \\
3,000\end{array}$ & $\begin{array}{l}5,333 \\
2,364\end{array}$ & $\begin{array}{l}1,866 \\
1,069\end{array}$ & $\begin{array}{r}220 \\
7 \pi\end{array}$ \\
\hline $\begin{array}{l}\text { hoOSING } \\
\text { FIN }\end{array}$ & $\begin{array}{l}\text { TENStIf } \\
\text { TESSIII }\end{array}$ & $\begin{array}{l}\text { 15.000 } \\
18000\end{array}$ & $\begin{array}{l}8.168 \\
18542\end{array}$ & $\begin{array}{l}5,002 \\
\text { ta } 100\end{array}$ & $\begin{array}{l}3,349 \\
7,474\end{array}$ \\
\hline \multicolumn{3}{|c|}{ MAX, DEFECTION AT H, 5, MID PLANE, INCH } & Q. ए? & Q. 014 & 10 013 \\
\hline
\end{tabular}

As can be soen. none of the stresses exceed the allowables, except for the shear stress at the ends of the heat source stack. But this may be an artifice of our analytical mode1, in which the axial spring forces were concentrated at the corners of the heat source stack. In actual practice, these forces would be spread out over larger areas by the nolybdenum cross-pieces, and those areas could be further enlarged by expanding the shoes of these cross-pieces.

Table VII appears to indicate a marginal condition for the fins during shuttle launch, but this is not so. At the shuttle launch temperatures the allowable stress is $21,000 \mathrm{psi}$, not $18,000 \mathrm{psi}$. Thus, the conputed stress under $40 G$ lateral and 116 axial is well within the allowable linit.

Finally, Figure 23 illustrates the computed static deformation of the heat source stack and the housing under a diagonal lateral load of $40 \mathrm{~g}$ together with an axial load of $11 \mathrm{~g}$. The dashed lines represent the original positions of the edge of the heat source stack and the column of nearest thermocouple hot shoes, with a normal design gap of 0.125 inch. The solid curves depict the corresponding profiles after deformation. As shown, the mininum gap after deformation is 0.087 inch.

In sumary, the detalled analysis described in this section demonstrates the structural viability of the basic scheme for supporting a long heat source stack without intermediate supports, under the anticipated static, dynamic, and thermal expansion loads.

rV. DESIGN OPTIMIZATION

Section II described the topology and major components of the RTG in general terms. This section describes a computer program which, for a given set of constraints and fixed input parameters, finds the combination of variable parameters which minimize the generator weight for a specified power level. The section also presents the results of the optimization for the power range of interest.
Fig. 23 - RADIAL DEFLECTIONS UNDER STATTC G-LOADS 406 LATERAL (DIAGONAL) PLUS IIG AXIAL

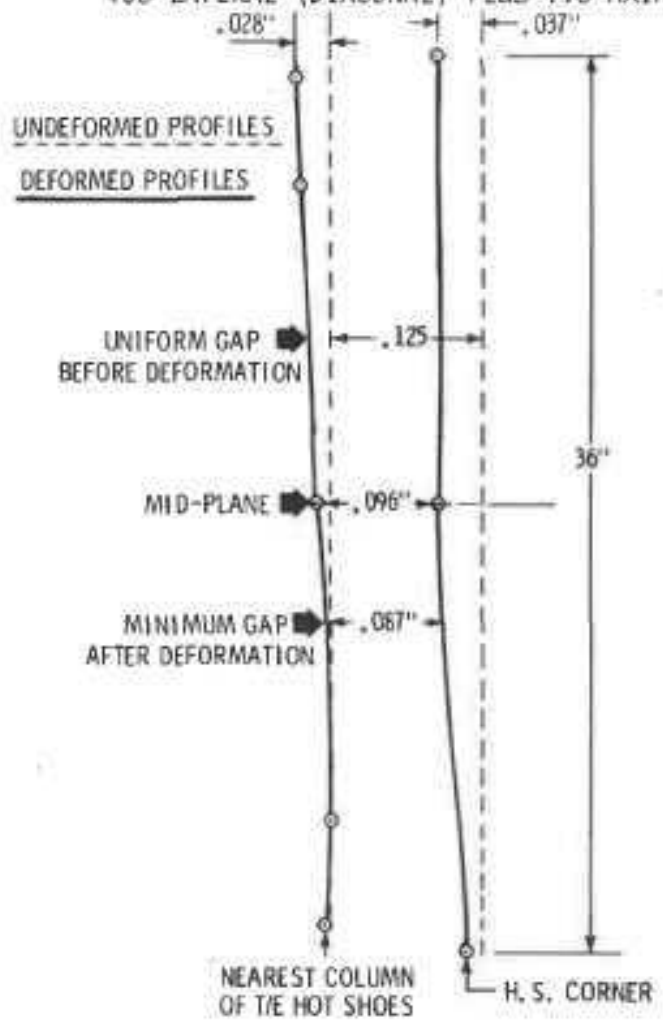

The fixed input parameters include the thermoelectric hot-junction temperature $\left(1000^{\circ} \mathrm{C}\right)$; the length $(1.23 \mathrm{in})$ and weight* $(0.0207 \mathrm{Ib})$ of each unicouple and of its associated mounting hardware $(0,0066 \mathrm{lb})$; the hot shoe size $(0.9 \times 0.9$ in), and the minimum gap between the hot shoes and the heat source corners $(0.125 \mathrm{in})$; the thickness $(0.70 \mathrm{in})$ and density $(0.021 \mathrm{ib} / \mathrm{cu}$ in) of the multifoil insulation*; the thermal conductance of the pyrolytic graphite buttons used to support the heat source, and the physical properties of the housing and radiator materials (beryliium, unless otherwise stated); the temperature drop between the unicouple's cold junction and its mounting point on the RTG housing $\left(30^{\circ} \mathrm{C}\right) *$; the assumed minimun.fabricable housing wal1 thickness $(0.060 \mathrm{in})$; the number of radiator fins ( 8$)$ and the minimun practicg 1 fin thickness $(0.020$ in); the weight $\left(0.008 \mathrm{gm} / \mathrm{cm}^{2}\right)$ and emissivity $(0.85)$ of the RTG's surface coating; the temperature-dependent Seebeck coefficient, resistivity, and thermal conductivity of Si-Ge; the prescribed output voltage (28v) of the ISPM generator; and the weight (3.32 1bs), diagonal dimension $(5.27 \mathrm{in})$, and height $(2.03 \mathrm{in})$ of the heat source module. The above parameters are held fixed during the optimization process.

The heat source module weight and size cited above, which represent the latest design option under test at LASL, were used as the basis for nost of the results presented below. Since the nodule's size and weight may change, dependiny, on the outcome of LASL's ongoing safety tests, the effect of different heat source options on generator weight is examined at the end of the paper.

The optimization program consists of four main parts: The first varies the variable parameters over specified ranges. The second calculates the pover output and RTG weight for any specific set of variable parameters. The third part examines the results of the thousands of cases analyzed in Parts 1 and 2 and picks the lightest design for any given power level.

basod on MHX information, with suitable adjustments 
And the fourth part of the program generates graphic and tabular output to display the results of the optimisation.

The variable RTG paraneters investigated include the number of 250-wate heat source modules $\{14$ to 20$\}$, the number of 16 -couple rings $(22$ to 40$)$, the number of couples in parallel ( 3 or 4 ) and implicitly the number of couples in series (128 to 192), and the radiator fin length (o to 12 inches) and fin base $(0.020$ to 0.180 inch $)$.

Given a set of those paraneters, the program first computes the length and thermal power of the heat source. It then calculates the heat losses through its support structure and through the multifoil insulation and along its joints with the thermocouples. The remainder is the heat flow to the couples.

Since the number of couplos in series and the RTG output voltage have been specified for a 5 pecific design point, the couple voltage is implicitly fixed. Note that in most cases this $\mathrm{kill}$ not be the voltage which maximizes the couple's efficiency. The program described here seeks to nininize the RTG's weight, not to maximizo its efficiency.

From the known couple voltage, the program next uses an Initial estimate of the cold-junction temperature to compute the thermoelectric efficiency of the couples. Once the heat flow to the couples and their efficiency are determined, the RTG's power output, systen efficiency, and theat rejection rate are. known. Also known are the RTG's internal impedance and therefore the lateral dimensions of the thermocouple legs. For the range of interest, the latter are within a few percent of the corresponding. values in the MHW design.

Next, the program performs a structural anaiysis to detornine the axial preload required to hold the heat source together during launch, the weight of the end caps neoded to sustain that preload, and the housing wall thickness needed to survive the shuttie and IUS launch loads.

In computing the required housing wall, the program checks three criteria: the tensile stress due to the preload combined with the lateral launch loads on the shuttle; ditto for the Ius launch; and the stability of the cantilevered housing wall under bending moments caused by lateral launch loads. There is an optional, fourth criterion: $a$ check for the wall thickness required to keep the cylindrical housing from collapsing when the external prossurc exceeds the inter. nal pressure by one atmosphere. But this criterion was generally not applied, because it was assumed that the generator would be stored, shipped, and launched while filled with more than one atmosphere of inert gas; and that it would only be tested under vacuum with the whole RTG contained in a vacuum chamber.

After determining the minimum wall thickness required to satisfy all of the above three (on four) structural critcria with appropriate safety margins, the progran chooses that thickness or the assumed lower fabrication limit for the wall material, whichever is greater. It then proceeds to analyze the heat rejcction system, using the previously computed heat loss rate through the insulation and heat rejection rate of the thernoelectric couples.

The prablem of designing a minimum-weight radiator fin for a given heat flow rate and root temperature has been solved elsewhere $[6,7]$ for various fin configurations and constraints. But those solutions. are only valid for fins with an inobstrueted view of space, and without internal nadiation interchange. They do not apply to the present case, where the view to space of the housing and fins is severely blocked, and where radiative interchange between those conponents is an important heat transfer mechaniso. With radiative interchange, the fin design optinizes at. different lengths and thicknesses.
The thermal analysis in the program is carried out for a 45-degree segment of the housing enclosed by two radiator fins. The fins are of trapezoidal cross-section, tapering from the fin root thickness under consideration to a 9.020 -inch fin tip thickness. The housing segment is divided into ten nodes, and each fin consists of 0 to 40 nodes (of approximately 0.3 inch), depending on the fin length under consideration. The thermoelectric hest rejection rate is applied at two housing wal: nodes which represent the unicouple mounting points.

For the above nodel of 10 to 90 nodes, the progran computes thermal conductances between adjacent. nodes, and radiation view factors between al1 node pairs which face each other. From these vien factors, it then computes radiation interchange factors, which take account of mutual reflections between nodes. The resultant natrix of interchange factors, containing as many as $90 \times 90$ terms for the mininum fin length, is then collapsed to one quarter that size, by taking advantage of the symmetry plane midway between the twe fints: and the temperatures of the renaining 5 to a5 nodes are computed by conventional matrix inversion methods.

of particular interest are the fin root temperature, the fin tip temperature, and the housing temperature at the unicouple mounting point. The latter is used to compute the cold-junction temperature, based on a $30^{\circ} \mathrm{C}$ cold-stack temperature drop. If the result does not agree with the previously assuned cold-junction temperature within prescribed convergence limits, the thermoelectric performance is recosputed for the new cold-junction temperature, and the entire therual analysis is repeated. This iterative process continues until convergence is achieved.

Once a consistent solution has been found, the RTG weight for the specifle set of input variables can be computed. Let us illustrate this for a typical case consisting of 18 heat source modules, 34 rings of 16 couples each, 4 couples in parallel and 136 in series. a fin length of 4.32 inches and root thickness of 0.092 inch. For this case, the heat source stack is 36.5 inches long, the converter cavity formed by the hot shoes has a dianeter of 5,52 inches, the generator housing has an outer diameter of 7.98 inches and a required wall thickness of 0.060 inch, and the RTG has an overall length (ircluding end caps) of 40.7 inches and a tip-to-tip span of 16.6 inches.

As iliustrated in Figure 24 , the converged solution gives a cold-junct ion temperature of $308^{\circ} \mathrm{C}$. The housing wall tenperature varies from $278^{\circ} \mathrm{C}$ at the unicouple mounting points to $265^{\circ} \mathrm{C}$ at the fin roots, and the fin tip temperature is $190^{\circ} \mathrm{C}$. As will be seen. such low fin tip temperatures, with correspondingly low fin effectiveness values, are typical for optinized radiator designs. Typical temperatures for the fuel capsule and heat source surface are also shown in Figure 24.
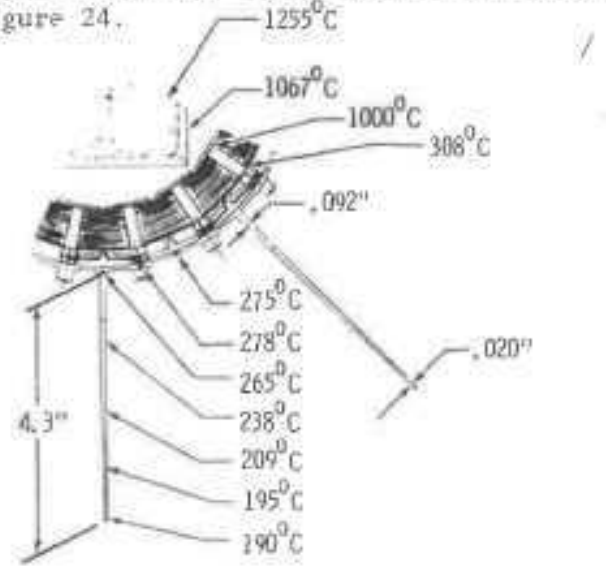
For the temperatures and dimensions given above, the heat losses consist of 168 watts through the heat source supports, 36 watts through the end foils, 94 watts through the stde foils, and 132 watts through the insulation joints. Thus, of the heat source's thermal power of 4500 watts, a total of 430 watts is lost, giving a thermal efflclency of $90.4 \%$ and leaving 4070 vatts as the heat input to the thermoelectric elements.

At the $1000^{\circ} \mathrm{C}$ hot-junction temperature and the $308^{\circ} \mathrm{C}$ cold-junction temperature, the maximum efficiency of the Si-Ge couples is $7.22 \%$ at an output voltage of 0.190 volts. But since the 1.36 couples in series must produce the specified output of 28 volts, the actual couple voltage for this case is 0.206 volts. At that voltage, the thernoelcctric efficiency is reduced to 7.17 \% .

Thus, for this specific case, the RTG has an output of 292 watts $(10.4$ amps at 28 volts), giving a system efficiency of $6.49 \%$. Its intornal impedance is 1.80 ohms, and the external load impedance is 2.69 ohms. The total heat rejection rate of the RTG is 4208 watts.

The weight breakdown for the fllustrated case is sunimarized in Table VII. As expected, the heat source stack is by far the heaviest component, constituting 58 of the total weight. The basis of most other component weights has beon discussed before. Whonover possible, they are scaled from weights of corresponding MHE components or from other GE information.

Table VII: WEIGHT SUMMARY (LBS)

FOR ILLIJSTRATIVE RTG DESIGN (292W BOL)

\begin{tabular}{|c|c|}
\hline $\begin{array}{l}\text { HEAT SOURCE MODULE: } \\
\text { Fuel } \\
\text { Iridium Capsules } \\
\text { Graphite Shells }\end{array}$ & $\begin{array}{r}24.21 \\
8.57 \\
26.98 \\
\end{array}$ \\
\hline $\begin{array}{l}\text { HEAT SOURCE SUPPORTS: } \\
\text { Moly Cross-Pieces } \\
\text { Pyrographito Buttons } \\
\text { Springs, etc. }\end{array}$ & $\begin{array}{l}0.50 \\
0.13 \\
0.40\end{array}$ \\
\hline $\begin{array}{l}\text { T/E CONVERTER: } \\
\text { Unicouples } \\
\text { Electrical Straps } \\
\text { Rivets \& Washers }\end{array}$ & $\begin{array}{r}11.60 \\
1.08 \\
0.63\end{array}$ \\
\hline $\begin{array}{l}\text { INSULATION: } \\
\text { Alumina Spacers } \\
\text { Side Insulation } \\
\text { End Insulation } \\
\text { Support Frame. }\end{array}$ & $\begin{array}{r}0.61 \\
10.33 \\
0.59 \\
1.50\end{array}$ \\
\hline $\begin{array}{l}\text { T/E MOUNTING: } \\
\text { Nut Plates } \\
\text { Mounting Flats } \\
\text { C-Seals } \\
\text { Mounting Screws }\end{array}$ & $\begin{array}{l}1.51 \\
0.83 \\
0.12 \\
1.46\end{array}$ \\
\hline $\begin{array}{l}\text { RTE ENVELOPE: } \\
\text { Housing } \\
\text { End Caps. } \\
\text { Radiator Fins } \\
\text { Mounting Pads } 6 \text { Bushings }\end{array}$ & $\begin{array}{l}3.88 \\
2.00 \\
4.80 \\
0.50\end{array}$ \\
\hline $\begin{array}{l}\text { EXTERNALS: } \\
\text { Power Connectors } \\
\text { Emissivo Coating } \\
\text { Gas Management System } \\
\text { Pressure Relief Device }\end{array}$ & $\begin{array}{l}0.25 \\
0.50 \\
0.29 \\
0.69\end{array}$ \\
\hline RIG TOTAL & 104.0 \\
\hline
\end{tabular}

One rather surprising item is the relatively high weight of the thermal insulation syster. At 10.9 lbs, which is 10.55 of the total system weight, it is almost as heavy as the $T / E$ converter, and substantially heavier than the RTG housing and the radiation fins.
The other iton worth noting is the insulation support frame. This has been included in all our calculations because it was part of GE's MHW design. However, it is not elear to the authors that this support frame performs any necessary function after the converter is assembled. The support frame in the MHW RTG is not connected to the housing, but floats on the inside of the multifoil package. The foil package itself, as stated by GE [3], is essentially supported by the thernoelenents. The weight of the support frame is apprectable, and its elimination would reduce the RTG's weight and improve its specific pover. However, before it could be eliminated, tests to confirm that it is not needed would first have to be performed.

For every combination of number of heat source modules, number of converter rings, and number of couples in parallel and series, the program repeats the above design point analysis for different fin lengths and root thicknesses, to find the variation of RTG powor and weight. Typical results are illustrated in Figure 25 , for the case of 18 heat source modules. 34 rings of 16 couples, 4 couples in parallel and 136 in series, and for fin lengths from 0 to 10 inches and root thicknesses from 0.020 inch to 0.140 inch. The fins are trapezoidal*, with a fin tip thickness of 0.020 inch. The results are displayed as weight-versuspower curves, with the dottod diagonals showing lines of constant specific power. Each curve is for a constant fin root thickness, and shows the variation of RTG weight and power as the fin length is varied. The left ends of all curves converge at a common point, which represents the case of zero fin length.

Fig. 25 - EFFECT OF FIN LEWGTH AND ROOT THICKNESS ON RTG WITH 18 H.S. MODULES, 34 RIMGS OF COUPLES, 4 IN PARALLEL

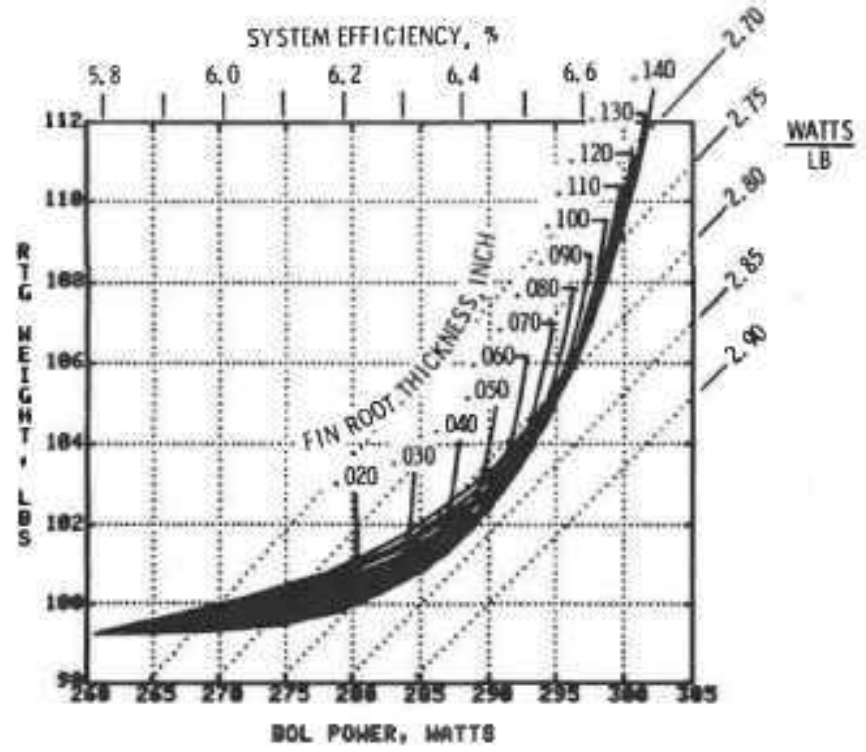

As can le seen, the specific powet of the RTG decreases for short fins and thin fins, because of increasing cold-junction temperature and reduced conversion efficiency; and it decreases for long fins and fat fins, becauso of increasing radiator weight. For every power level, there is an optimus combination of fin length and root thickness which ninimizes the RTG weight. This is illustrated by the curve in Figure 26, which represents the envelope of the family of curves shown in Figure 25 .

a somewhat lighter design is possible by using curved instead of tapered profiles, but this was not used because of its relatively saall benefit and because of concern about its fabricability. 
Fig. 26 - OPTIMUW FIN OTMENSTONS FOR ILLUSTRATTVE CASE

\section{SYSTEM EFFICIENCY, 3}

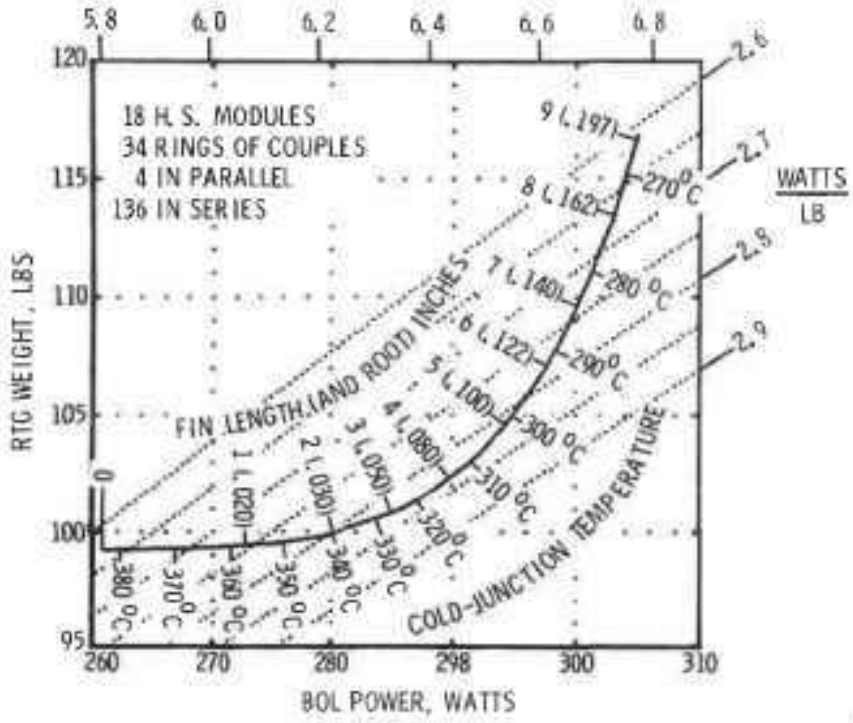

The tick aarks in the above figure indicate the optimun fin length and root thickness at each point and the resultant cold-junction teaperature. The? corresponding system efficiencies are shown at the top of the figure. The left end of the curve, and of similar curves in subsequent figures, represents the case of a fin-less RTG housing. For the set of parameters examined in Figure 26 , it can be seen that the specific power has a broad maximum at a fin length of about 4 inches and a root thickness of 0.080 inch. This corresponds to a radiator weight of 3.2 lbs, a cold-junction temperature of about $314^{\circ} \mathrm{C}$, and a system efficiency of 6.445. Considerably higher efficiencies can be achieved with longer fins, but at much higher weights. For oxample, Figure 26 shows that at a fin length of 8 inches the optimum $f$ in root thickness is 0.162 inch, which yields a cold-junction temperature of $276^{\circ} \mathrm{C}$ and a system efficiency of 6.735 , but results in a radiator weight of 14.0 lbs for the eight fins.

For the case of 18 heat source modules, 4 couples in paralle1, and optimized radiator fins, Figure 27 illustrates the offect of varying the number of 16 couple rings on the weight-versus-power curves. Varying the number of couple rings affects the total

Fig. 27 - EFFECT OF NUMBER OF 16-COUPLE RINGS ON RTG WITH 18 HEAT SOURCE MODULES

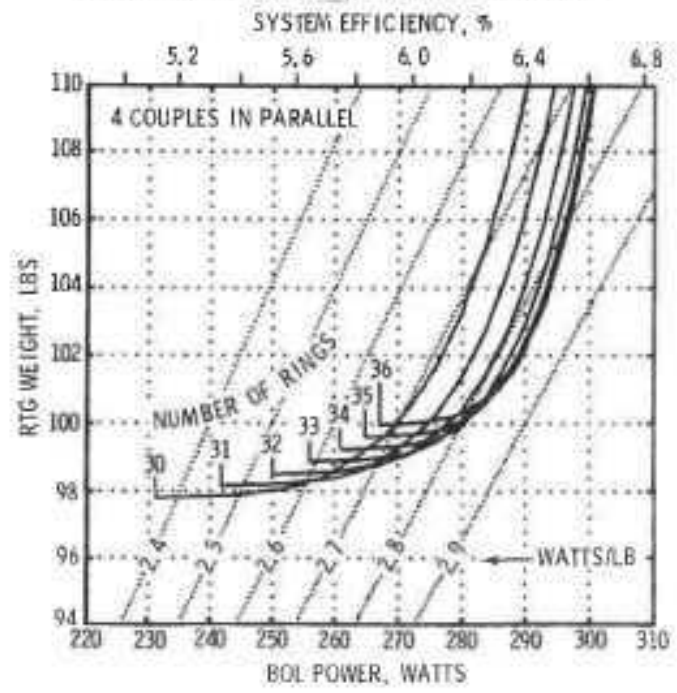

weight of the couples. Since the output voltage and the number of couples in parallel is fixed, it also affects the voltage per couple. Excessive deviation from the optimun couple voltage lowers the converston efficiency, and therefore the output power. Below a certain number of couple rings, this effect outweighs the weight reduction due to the reduced number of couples, leading to reduced power-to-weight ratios. Therefore, as can be seen, there is an opt inum number of couple rings, though generally not the sane optinuti for all power levels.

The number of couple rings is limited by the maximun number which can be accomodated in the available converter Jenpth without risk of contact between adjacent hot shoes. I $\pi$ general, the maximum number of rings considered in our study was two rings per heat source module. This limit could, of course, be avoided by using sraller hot shoes, but this would have violated DOE's instructions to Fairchild,

The additional effect of varying the number of heat source modules is illustrated in Figure 28. The figure presents curves of RTG weight versus power for 14 through 20 heat source modules and various numbers of couple rings (up to the geometric limit). The figure represents thousands of individual design points. In the curves shown, dashed lines are used to represent cases where the latera1 dimensions of the couple 1 legs is less than 1008 or more than 110 \% of the corres. ponding dinension in the MHW design. As can be seen, most points in the region of interest fall within these linits.

Fig. 28 - RTG DEIGHT-VERSUS-POLER CURVES FOR VARIOUS NLMBERS OF H.S. MODULES AND CONVERTER RINGS

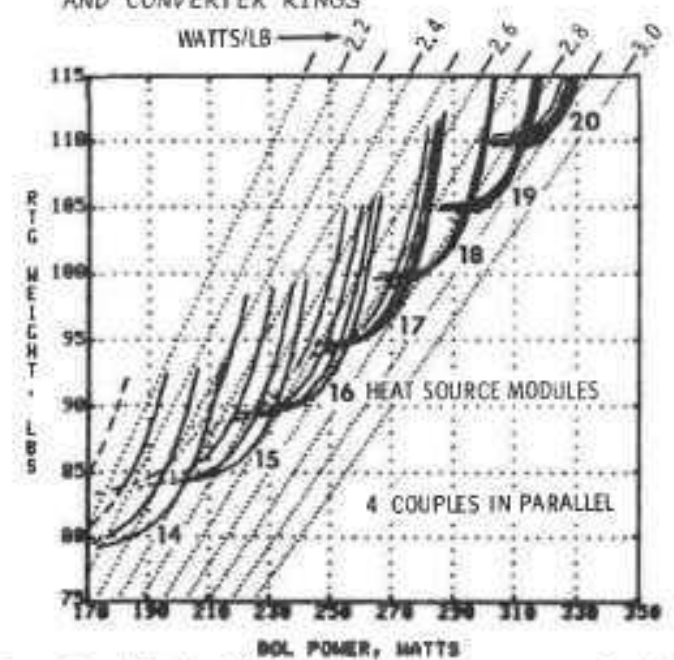

Part 3 of Fairchild's computer program is designed to find and plot the maximum-specific-power envelope from a large data set, such as the one illustrated in Figure 28. For a given power level, it examines every curve in the data set point-by-point, finds the corresponding RTG weight by interpolation, and determines what number of heat source modules and number of converter rings gives the lovest weight. The results are presented graphically and in tabular form.

Figure 15 shows curves of ninimum RTG weight versus power for each number of heat source modules, from 14 through 20 (discarding all data points for which the leg dimensions do not fall within 100 to $110 \%$ of the corresponding. MtiW dimensions). As can be seen, for every power level there is an optimum number of heat source modules which minimizes the RTG weight. In selecting a design, it may be desirable to deviate fron this optinun; e.g. . to use a smaller-than-optiaum number of heat source modules to reduce fuel inventory and/or RTG length. Figure 29 shows the weight penalty For this kind of design trade-off. 
FIg. 29 - ENUELOPE OF RTG WEIGHT-VERSUS-POWER CURVES FOR EACH NUMBER OF HEAT SOURCE MOOULES

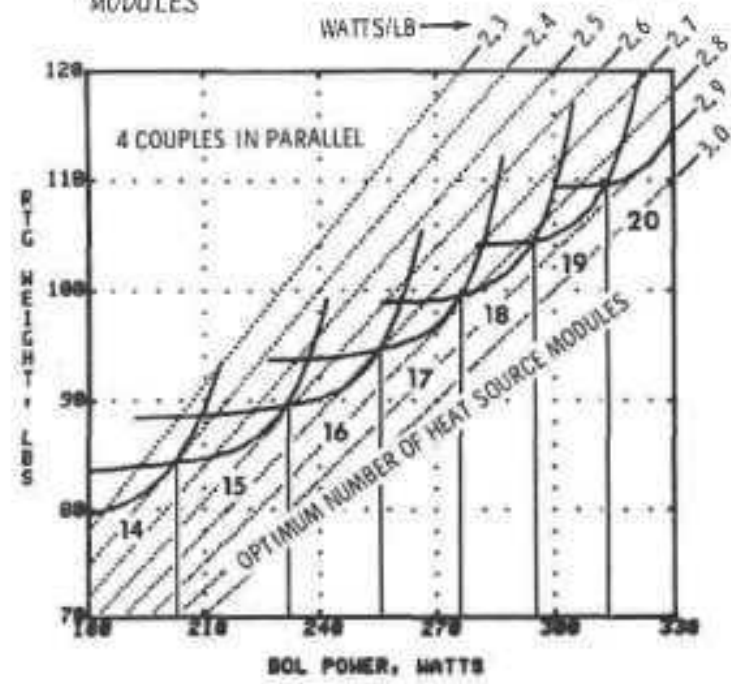

As seen, the naxinum specific power decreases at the lower power levels. To some extent this is to be expected, since end losses and end section weights becone more significant in smaller RTGs. But there is another important reason for the lower specific power levels: As the number of heat source modules is reduced, the number of couple rings which can be accorveodated goes down. As the maximum number of couple rings drops significantly below its optimum value, the efficiency goes down, which lowers the specific power.

Thus, below a certain power level, a lighter RTG design can be obtained by using 3 instead of 4 couples in parallel. This increases the couples in series and reduces the voltage per couple. This effect is 11lustrated in Figure 30. The curve 1abeled 4-4 represents the master envelope of all the-curves shown in Figure 29 ; 1.e., the lightest solutions with 4 couples in parallel. Only lata points in which the thermoelectric legs' latera! dimensions fall between $100 \%$ and $110 \%$ of the MHN values have been included.

Fig. 30 - ENVELOPES OF RTG WEIGHT-VERSUS-POWER CURVES FOR 3 AND 4 COUPLES IN PARALLEL

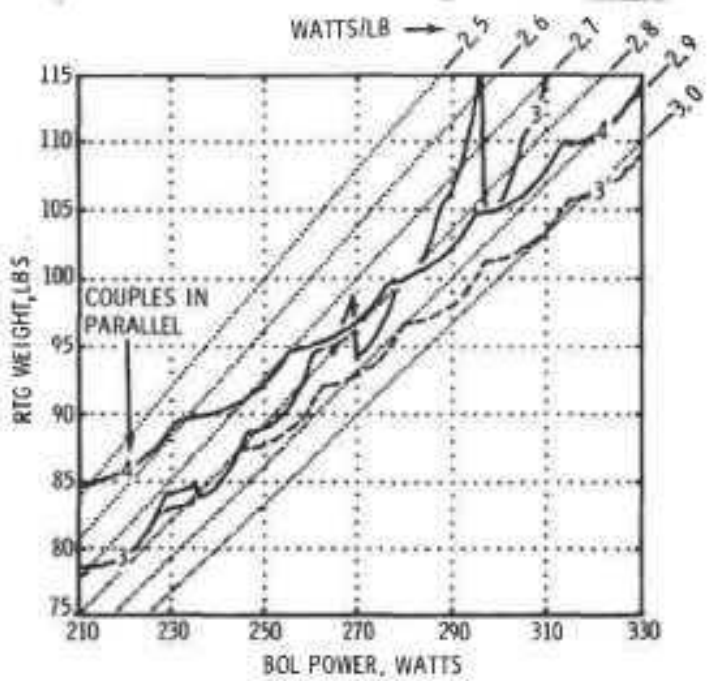

The dashed curve labeled $3-3^{\prime}$ represents the lightest solutions for 3 couples in parallel, before the above geonetric limit is applied. As can be seen, without that limit the 3-in-paralled design gives consistently lower RTG weights, over the entire power range. Fewer couples, with fatter legs, yield a lighter gencrator. But most of the points on the dashed curve represent designs in which the lateral leg dimensions exceed the MHK value by more than $10 \%$, which violates our ground rule. When these points are discarded, the solid curve labeled $3-3$ is obtained. This represents the lightest solutions with 3 parallel couples satisfying the geometric ground rule. The imposition of that ground rule accounts for the very jagged appearance of this and some later envelopes.

Figure 30 shows that, even with the geometric constraint, the 3 -in-parallel design is superior for power levels up to about 280 watts. Only above that power are 1 ighter RTGs obtained with 4 couples in parallel. The superiority of the 3 -in-parallel design over much of the power range was unexpected, because that design is not well adapted to the basic arrangement of 16 couples per ring, since 16 is not a multiple of 3 . As illustrated earlier in Figure 26 , with a 4-in-parallel circuit, any nuaber of couple rings can be used to optimize the RTG design; but with a 3-inparallel arrangement, the number of couple rings must itself be a multiple of 3 . Because of this constraint, the three-in-parallel design cannot be optimized as well as the 4-in-parallel case.

For each power level skown, the envelope of the two solid curves in Figure 30 represents the minimum RTG woight for the set of fixed parameters listed at the beginning of this section. As seen, for most of the power range the lightest systen yields a specific power between 2.7 and 2.9 watts/1b. The variable design parameters which produce these minimum weights are suamarized in Table VI11. For each power level from 220 watts to 330 watts, the table gives the optimun number of heat source modules, number of 16-couple rings, number of couples in parallel and series, optimun $f$ in length and root thickness; the resultant cold-junction, fin-root, and fin-tip temperatures; the lateral dimensions of the thermoelectric legs compared to those in the MHW RTG; the thermal, thermoelectric, and system efficiencies; the RTG weight and specific power.

For the power range from 220 to 330 watts BOL, the optimum design calls for: 14 to 20 heat source modules, with corresponding lengths of 28,4 to 40.5 inches for the heat source stack, 26.4 to 38.5 inches for the radiator fins and 32,5 to 44,6 inches for the total RTG: 432 to 592 thernoelectric couples, arranged in 27 to 37 rings; 136 to 176 couples in series, with 3 in parallel at lower power level 5 and 4 in parallel at the upper end of the power range; and fin lengths ranging from 0.92 inch to 6.58 inches, with corresponding root thicknesses of 20 to $134 \mathrm{mils}$, and RTG spans from 9.8 to 21.1 inches. These design optina yield temperatures of 296 to $359^{\prime \prime} \mathrm{C}$ for the cold junctions, 252 to $320^{\circ} \mathrm{C}$ for the fin roots, and 153 to $293^{\circ} \mathrm{C}$ for the fin tips; thermoelectric legs 2 to 105 thicker than the MHW design; thermal efficiencies of 88 to $91 \mathrm{~s}$, thermoelectric efficiencies of 6.8 to $7.3 \%$. and system efficiencies of 6.1 to 6.65 . The minimum RTG weights range from 79.5 to $114.51 \mathrm{~b} 5$, and the maximum specific power generally 1 ies between 2,7 and 2.9 watts per $1 \mathrm{~b}$.

There are a number of interesting tendencies to be noted in Table VIII. The fact that 3-in-parallel cireuits give lower weights than 4-in-parallel networks over much of the power range has already been mentioned. The optitum number of couple rings is generally lower than the geometric limit of two rings per heat source modulo. The optimum radiator has relatively short fins, even though this leads to high cold-junction temperatures and low efficiencies. The benefits obtained by longer fins do not compensate for the resultant radiator weight increase, Similarly, the optinum fins have relatively thin roots, even though this leads to large fin temperature drops and low fin effectiveness. Particularly noteworthy is the narrow range of the maximum specific power over the wide power range examined. 
Table VIII: OPTIMUM DESIGN PARAMETERS

\begin{tabular}{|c|c|c|c|c|c|c|c|c|c|c|c|c|c|c|c|}
\hline \multirow[b]{2}{*}{$\begin{array}{l}\frac{3}{2} \\
\alpha \\
\frac{x}{0} \\
\frac{1}{8} \\
8\end{array}$} & \multicolumn{4}{|c|}{ OPTIMUM DE $\overline{5}$} & \multicolumn{2}{|c|}{ FIN } & \multicolumn{3}{|c|}{ IEnP. OC } & \multirow[b]{2}{*}{ 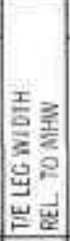 } & \multicolumn{3}{|c|}{ S EFFICIENCY } & \multirow[b]{2}{*}{ 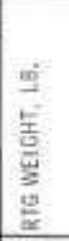 } & \multirow[b]{2}{*}{$\begin{array}{l}\frac{10}{3} \\
\frac{2}{5} \\
\frac{5}{5} \\
8 \\
0 \\
0 \\
0\end{array}$} \\
\hline & 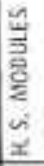 & $\frac{\tilde{s}}{\Sigma}$ & $\begin{array}{l}\frac{\vec{d}}{a} \\
\frac{\alpha}{a} \\
\frac{a}{2}\end{array}$ & $\frac{\frac{n}{2}}{\tilde{g}}$ & $\frac{\bar{z}}{\frac{2}{5}}$ & 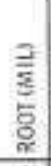 & $\begin{array}{l}\frac{1}{0} \\
\frac{2}{2} \\
\frac{9}{3} \\
0\end{array}$ & $\begin{array}{l}5 \\
\text { 总 } \\
\underline{z} \\
\end{array}$ & $\frac{a}{z}$ & & 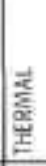 & 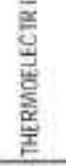 & $\frac{\bar{w}}{\frac{5}{5}}$ & & \\
\hline 220 & 14 & 21 & 3 & 144 & 2.66 & 45 & 331 & 290 & 225 & 1.05 & 89 & 3.03 & 6.29 & 79.5 & 2.77 \\
\hline & 1.8 & 27 & & 144 & & 51 & 323 & 281 & & & 89 & & & 0.0 & 2.77 \\
\hline & . & 27 & 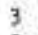 & 144 & & $\phi \hbar$ & 314 & 272 & 183 & & 88 & & & & 2.77 \\
\hline 226 & 14 & 27 & & 144 & & 92 & 306 & 262 & 180 & & 88 & 7.27 & & 20 & 2.76 \\
\hline 228 & 14 & 27 & 3 & 144 & 56 & 114 & 296 & 253 & 168 & 1.02 & 84 & T. 90 & 6. 51 & 83,6 & 2.73 \\
\hline 230 & D. & 0 & . & $I 6 x$ & & 20 & $3 \Leftrightarrow$ & 320 & 293 & 05 & 84 & & & 12 & 18 \\
\hline 232 & 15 & 30 & 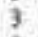 & 160 & & 24 & 950 & & & & हम & & & & 75 \\
\hline 234 & 1 & 30 & 3 & 160 & & 32 & 341 & & 0 & & $=$ & & & & 77 \\
\hline 236 & 15 & 27 & 3 & 144 & & 43 & $33 \%$ & 294 & 237 & & $\log _{00}^{0 .}$ & & & 8.8 & 2,81 \\
\hline 238 & 15 & 27 & 3 & 144 & $n$ & 4 & 328 & 286 & 200 & L. D9 & 80 & 7.10 & 6.35 & 43 & 282 \\
\hline 240 & 3 & 27 & 3 & 144 & & 51 & 321 & 278 & 196 & & 70 & & & 9 & 2.02 \\
\hline 242 & 17 & 21 & 3 & 144 & & 72 & 313 & 270 & 184 & & & & & & .82 \\
\hline & 15 & $2 \pi$ & 3 & 144 & & 92 & 304 & 261 & 6 & 08 & 89 & & & 9 & .81 \\
\hline & is & 27 & 3 & 144 & & 115 & 296 & 252 & 168 & 1.06 & 139 & 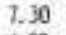 & & 8. 5 & 278 \\
\hline & 16 & 30 & 3 & 160 & & $x 7$ & 354 & 314 & 277 & 1.08 & 89 & & & 8. 6 & 97 \\
\hline & 1 & 30 & 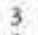 & 160 & & 24 & 346 & & 250 & & 90 & & & 0 & Not \\
\hline & 7 & 30 & 3 & 160 & & A3. & 337 & 296 & 245 & 1.07 & 189 & & & & 82 \\
\hline 4 & i & 30 & 3 & 100 & & 5 & 328 & 286 & 214 & & 89 & & & 3.0 & 82 \\
\hline & 1 & 30 & 3 & 160 & & 6 & 319 & 276 & 197 & & 90 & & & 8 & 8 \\
\hline & 10 & 30 & 3 & 160 & 32 & 8 & 309 & 266 & 188 & & 189 & & & 21 & 8 \\
\hline & I & 30 & & & & & . & 255 & & & 90 & & & & 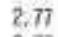 \\
\hline & 11 & 33 & 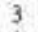 & 176 & 4 & 6 & 344 & 303 & & & 90 & & & & 77 \\
\hline & 11 & 33 & 3 & 136 & 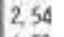 & 43 & 333 & 292 & 228 & & 90 & & & & $n$ \\
\hline 266 & 1 & $2 i$ & 3 & 144 & 58 & 134 & 287 & 24 & 153 & & 39 & & & & 78 \\
\hline & 17 & 34 & 4 & 135 & & 06 & 327 & & 210 & & 90 & & & ? & \\
\hline & 15 & 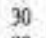 & 3 & & & & & & & & & & & & \\
\hline & 1 & 30 & - & 160 & & & 325 & & & & & & & & .87 \\
\hline & 1 & 30 & 3 & 160 & 70 & (6) & 316 & 274 & 200 & & 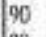 & & & & 2.80 \\
\hline 6 & 11 & 30 & 3 & 160 & $4 l$ & 92 & 397 & 264 & 186 & & 90 & i & & 2 & 2.8 \\
\hline 278 & 17 & 30 & 3 & 160 & 48 & 111 & 297 & 254 & 169 & 1.07 & 90 & 1.20 & ( & 9.1 & 28 \\
\hline & & & & & & & & & & & & & & & \\
\hline & 18 & 35 & 4 & 10 & & 1 & & 3 & & & 2) & & & & 2.8 \\
\hline & 11 & 34 & 4 & 136 & & & $3 \times 0$ & 2 & 2 & & 90 & & & & \\
\hline & 79 & 34 & 4. & 136 & & & 325 & 283 & 212 & & 90 & & & & 2.85 \\
\hline 288 & 78 & 35 & 4 & 10 & 0 & 36 & 324 & 282 & 213 & 105 & 90 & 0 & 0 & .5 & 28 \\
\hline & 18 & . & 4 & & & & & & & & 90 & & & & \\
\hline & 28 & 35 & 4 & 140 & & 7 & 2 & 269 & & & 0 & & & & 83 \\
\hline & 18 & 35 & 4 & 140 & & 9 & & 263 & & & 90 & & & & 82 \\
\hline 296 & 19 & 36 & 4 & 144 & & 21 & 352 & 312 & & & $9 !$ & & & & 2.83 \\
\hline 298 & 19 & 33 & 3 & 176 & 100 & $\Delta$ & 332 & 20 & 229 & 10 & 90 & 690 & & X.6 & 2.85 \\
\hline & 19 & & 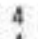 & & & & & & & & 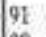 & & & & 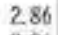 \\
\hline & 19 & 35 & 4 & 140 & & & 333 & 291 & & 9 & 90 & & & & 86 \\
\hline & 19 & 35 & 4 & 190 & & & 327 & 280 & & & 91 & & & & 2.87 \\
\hline 306 & 19 & 35 & 4 & 140 & & & 322 & 200 & & & 90 & & & & 2.88 \\
\hline 308 & 19 & 35 & 4 & 140 & 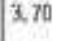 & th & 316 & 274 & & 1. 08 & 91 & 7,11 & 6. 48 & 07.0 & 2.88 \\
\hline & & & & & & & & & & & 30 & & & & 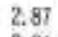 \\
\hline & 19 & 35 & 4 & 140 & & 92 & 305 & 262 & 179 & & 91 & & & 1 & 2,86 \\
\hline & 20 & 30 & 4 & 152 & & I & 352 & 313 & 270 & & 91 & & & & 2,85 \\
\hline 316 & 20 & 37 & 4 & 148 & & 24 & 346 & 396 & 253 & & 甲1 & & & 97,8 & 2,88 \\
\hline 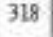 & 27 & 37 & 4 & 148 & & 33 & 341 & 300 & 280 & & 90 & & b. & 1101 & 2.89 \\
\hline & $\infty$ & & 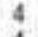 & & & & & 294 & & & L: & & & & $\pi$ \\
\hline ? & 23 & 37 & 4 & 148 & & 5 & 327 & 288 & 220 & & 91 & & & & 2,90 \\
\hline 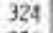 & 20 & 32 & 4 & 143 & & 55 & 323 & 232 & 213 & & 91. & & & & 2.91 \\
\hline 326 & 23 & 37 & 4 & 148 & 99 & 63 & 317 & 275 & 194 & L. 07 & 90 & & & 112.3 & 2.90 \\
\hline 328 & 20 & 37 & 4 & 148 & 4.32 & 75 & 311 & 288 & 185 & 1.07 & 01 & 2.22 & a. 56 & 113,3 & 2.90 \\
\hline 924] & 2.21 & 37 & 4 & 148 & .86 & 4 & 305 & 262 & 180 & L. 06 & 30 & 7.27 & 6. 80. & 145 & 2.8 \\
\hline
\end{tabular}

Figure 31 shows a comparison of one full-power RTG with two half-power RTG5. The lowor curve is the envelope of the two curves shown in Figure 30 ; i.e., the minimum-RTG-weight envelope for the stated assumptions, The upper curve shows a similar weight envelope for the case of two fdentical RTGs, each producing half the power at half the voltage.
Fig. 31 - COMPARTSON OF ONE FULL-POWER RTG WTTH TWO HIALF-POWER RTGS

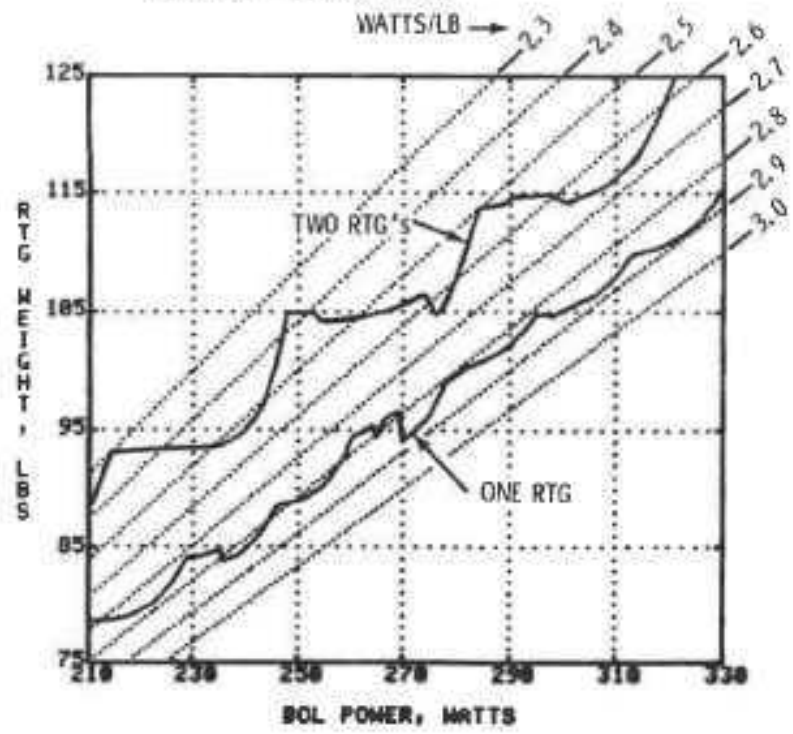

As would be expected, for any given power level the two-RTG case is appreciably heavier than the single generator. This is partly because of the weight and heat losses of the additional end sections; and partly because, for the case of two identical RTGs, the total number of heat source modules can only be varied in steps of two, which explains the deep scallops in the curve for two RTGs.

The weight difference shown in Figure 31 represents only the difference in actual RTG weights. It does not include any additional structural support weight required for the two-RTG case, Nor does it take note of the overall length increase (about 6 inchos) which would result if the two RTG were stacked end-to-end.

Next, let us examine the sensitivity of the RTG weight to the heat source nodule design parameters, comparing the heat source design analyzed thus far with two other design options tested earlier at LASL. In the order of increasing weight, these will be referred to as Option A. B, and C. Coption B, the hest source module design used in the preceding analysis, is depicted in Figure 32 ).

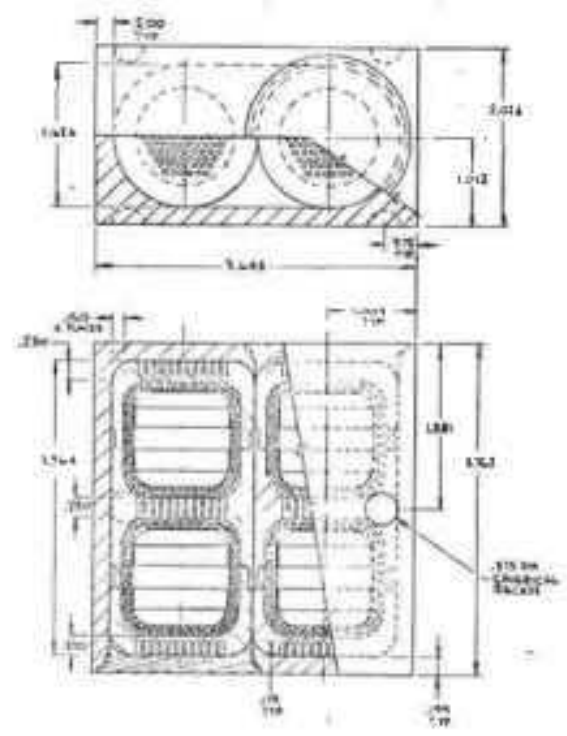

Fi.g. 32 - HEAT SOURCE MODULE DESIGH, OPTION B 
A11 three designs use identical fuel pellets. iridium capsules, and double pyrolytic graphite shells. The main difference between them is in the design of the 3D-graphite impact shells and aeroshells. In the Option A and B designs, two fuel capsules arc contained in a single impact shell with a 0.150 -inch side wal1. The end walls and the wall between the two capsules is 0.150 inch thick in Option $A$, and 0.230 inch in Option B. The Option C design uses a separate impact shell for each fuel capsule, with wall thicknesses of 0.200 inch. All three designs use a minimum aeroshell thickness of 0.200 inch. But in the 0ption $A$ and $B$ designs the aeroshell is hollowed out, and there is no gap between adjacent inpact shells; while in the third design the aeroshell is not hollowed out, except for the necessary fuel cavities, which are separated by a minimun 0.050 inch of 3D graphite. The three modules have respective heights of 2.02 , 2.03, and 2.11 inches; diagonal dimensions of 5.06. 5.27 , and 5.46 inches; weights of $3.15,3.32$, and $3.61 \mathrm{lbs}$; and specific powers of $79.5,75.3$, and 69,3 thermil watts per ih.

The effect of these heat source destgn differences is illustrated in Figure 33. The Option B curve is the envelope of the two curves shown earlier in Figure 30. The other curves represent the corresponding envelopes for Options A and C. As can be seen, variations in the heat source design have an appreciable effect on RTG weight.

Fig. 33 - EFFECT OF HEAT SOURCE OPTION ON RTG WEIGIT, AND COMPARISON WITH MHW

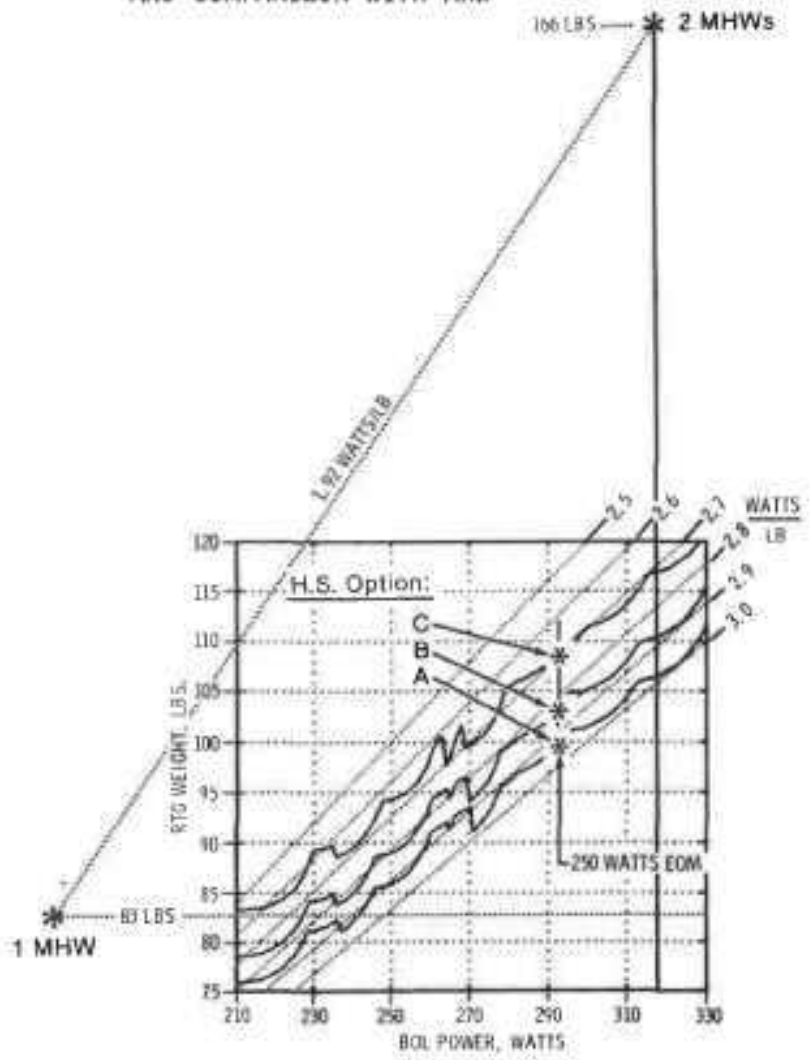

Figure 33 also shows a weight comparison of the ISPM RTG with the MiN RTGs used in previous missions. Based on measured MiW degradation rates, the present ISPM power specification of 250 watts at the end of mission (EOM) requires a BOL power of 292 watts. For that BOL power, the figure shows that the RTG described in this paper would weigh 100,103 and 108 lbs, respectively, for heat source options A, B, and C. By comparison, meeting the ISPM goal of 250 watts EON would require two MHW generators, weighing a total of 166 ibs.
It is recognized, of course, that we are comparing an actual-hardware design with a paper design which could grow significuntly during its developzent. But the paper design, except for the heat source, is based largely on the sate components as the hardware design. And the weight difference between them is so large that the design described here could grow substantially and still be a much lighter solution for ISPM than the MilW option.

Finally, let us briefly examine the effect of the choice of housing and radiator material on RTG weight. All the results presented thus far have been for beryllium. At typical wall temperatures of 250 to $300^{\circ} \mathrm{C}$, the mechanical strength of aluninum and magnesium alloys is so low as to nake these materials Unattractive from a weight viewpoint.

But the ISPM RTGs will in any case have to be cooled during the shutt le launch phase, Cooling will be by a circulating kater loop, delivering the reject heat to a water boiler which discharges the resultant steam outside the shuttle. Therefore, it would be possible to maintain the RTG housing at a relatively low temperature, e. 8 ., below $100^{\circ} \mathrm{C}$, during the shutt 10 taunch phase. This would gain the benefit of high material strength when it is nost needed, i.e., when 1 aunch loads sre most sovere.

It is true, of course, that the RTG must also survive the IUS launch loads, after the spacecraft has left the shuttle and its auxiliary cooling system. Therefore, during IUS firings, the RTG housing would be at its normal operating temperature of $250-300^{\circ} \mathrm{C}$. and hence aluminum or magnesium would be in a weakened condition. But this may not be too serious, because the IUS launch loads are less than half as high as the shuttle launch loads.

Figure 34 presents a weight comparison of RTGs with beryllius, aluninum $(2219-T 851)$, and magnesium (HM31A) housings and fins. The different densities, strengths, and thermal conductivities of these materials were taken into account. The analysis assuned transyerse launch loads of 406 at $90^{\circ} \mathrm{C}$ for the shuttle, and $20 \mathrm{G}-a t 300^{\circ} \mathrm{C}$ for the rus.

Fig. 34 - EFFECT OF HOUSTNG AND FIN MATERIAL ON RTG WETGHT

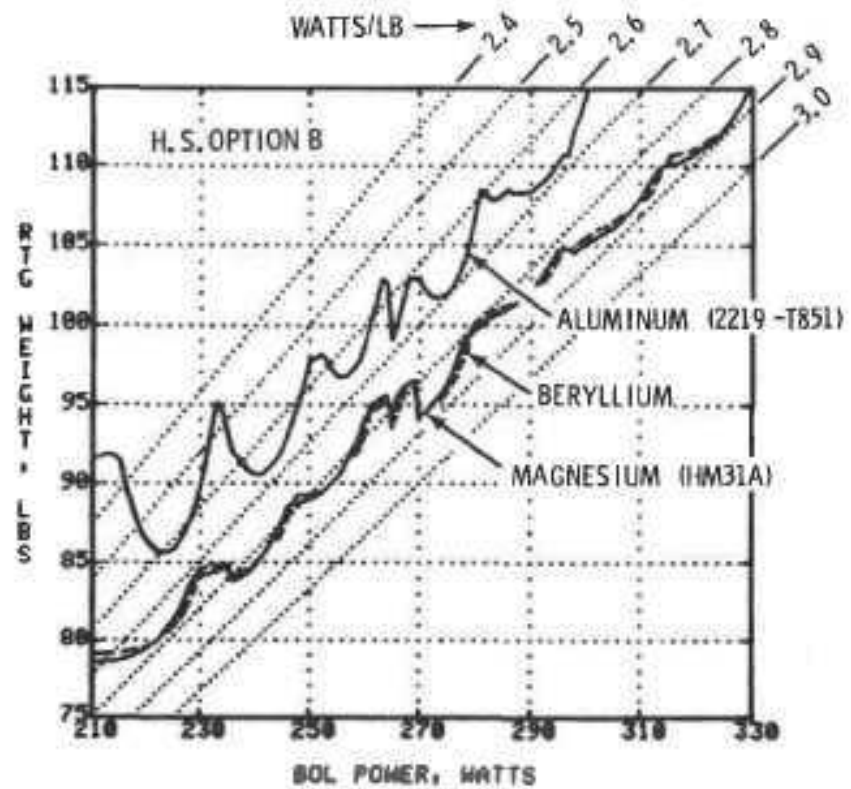

For the above assumptions, ligare 34 thows that magnesium gives almost the same RTC weight as berylliun. Mluminum gives appreciably higher weights, but these could be brought much closer to those for the other Elloys if, because of its sunerior machinahility, the minimum housing wall thickness could be reduced from 
0.060 to 0.040 inch. Whether such a thin-walled housing could be fabricated is still under investigation, as is the question whether aluminum or nagnesium could be used without excessive creep deformation during launch. In view of the difficulty and cost of fabricating and joining beryllium parts, the use of the other alloys seems well worth further exploration.

\section{SUMMARY AND CONCLUSIONS}

A conceptual RTG design which is substantially 1ighter than the MHW design using the same thermocouples and insulation kas generated. The RTG employs a stack of 18 heat source modules instead of a single, monolithic heat source.

A light-weight support structure for holding the heat source stack together without internediate supports was designed. A detailed static and dynamic analysis of the RTG confirmed the structural viability of the design under predicted launch loads and thermal expansion effects.

An RTG optimization progran was developed which, for the basic design topology and for a stipulated set. of assumptions, ground rules, and constraints, can rapidly determine the paraneters which yield the lightest RTG design for a given power level. The progran can casily be adapted to different sets of assumptions. The prograr was applied to parametric analyses of ISPM RTGs, with resules leading to the following conclusions:

1. Even though the heat source therfal power can only be varied in steps of 250 watts, the RTG output power is infinitely variable, by adjusting the other design parameters.

2. With optimized designs, the maximum specific power varies very little $( \pm 3 \%)$ over the wide power range investigated ( 210 to 330 watts).

3. RTG weights tend to minimize at relatively high cold-junction temperatures, with relatively short and thin radiator fins, even though efficiencies could be increased by using heavier radiators.

4. Over much of the power range investigated, a circuit with three couples in parallel gives a lighter RTG than one with four in parallel.

5 . Over the power range investigated, two halfpower RTGs would be considerably heavier than one ful1-power RTG.

6. RTG weights are quite sensitive to differences between the heat source module designs under current study.

7. Even the most conservative heat source module design under current consideration yields a much lighter power system for ISPM than would the previously used MHN RTGs.

8. For a shuttle-launched space mission, where auxiliary cooling must in any case be provided while the RTGS are inside the shuttle bay, the use of aluninun or magnesium alloys for the RTG housing and fins may be feasible.

9. The use of these alloys instead of beryllium would increase RTG weights only slightly, and should substantially reduce fabrication problems and costs.

\section{REFERENCES}

[1] JPL No. 660-57, NASA/ESA Out-of-Ecliptic Mission Description, 3 May 1977.

[2] Kelly, C.E., Loffreda, J.A, , and Lorentzen, R., "Performance Models for the MHW Converter", 8th IECEC Proceedings Addendum, Univ, of Penn, pp 37-46, 1973.

[3] Kelly, C.E., Wiley, R.L., and Lorentzen, R., "Thermal Performance of Foil-Insulated SiGe Converters". 8th IECEC Proceedings Addendum, Univ, of Penn., pp $47-54,1973$.

[4] "The NASTRAN Theoretical Manual (Level 17,5)", NASA-SP-221 (05), December 1978.

[5] "The NASTRAN Users Manual (Level 17.5)", NASA-SP-222(05), December 1978.

[6] Wilkins, J.E., Jr., "Minimum Mass Thin Fins for Space Radiators", Proceedings of the 1960 Heat Transfer and Fluid Mechanics Institute", (D.M. Mason et a1, ed.). Stanford Univ., pp 229-243, 1960 .

[7] Wilkins, J.E., Jr., "Minimum Mass Thin Fins with Specified Minimum Thickness", J, Soc. Indust. App1. Math., Vo1. 9, No, 2, pp 194-206, 1961.

\section{ACKNOWLEDGMENT}

The authors wish to express their appreciation to T, Kline and P. Larkin of Fairchild Space and Electronics for their contributions to the above work. 